\title{
Effect of Normobaric Hypoxia on Alterations in Redox Homeostasis, Nitrosative Stress, Inflammation, and Lysosomal Function following Acute Physical Exercise
}

\author{
Mateusz Maciejczyk (D, ${ }^{1}$ Anna Zalewska $\mathbb{D}^{2},{ }^{2}$ Małgorzata Gryciuk, ${ }^{3}$ Katarzyna Hodun, ${ }^{4}$ \\ Miłosz Czuba, ${ }^{5}$ Kamila Płoszczyca, ${ }^{6}$ Małgorzata Charmas, ${ }^{7}$ Jerzy Sadowski, ${ }^{7}$ \\ and Marcin Baranowski ${ }^{4}$ \\ ${ }^{1}$ Department of Hygiene, Epidemiology and Ergonomics, Medical University of Bialystok, 2C Adama Mickiewicza Street, \\ 15-022 Bialystok, Poland \\ ${ }^{2}$ Department of Restorative Dentistry and Experimental Dentistry Laboratory, Medical University of Bialystok, 24A Marii \\ Sklodowskiej-Curie Street, 15-276 Bialystok, Poland \\ ${ }^{3}$ Students Scientific Club "Biochemistry of Civilization Diseases" at the Department of Hygiene, Epidemiology and Ergonomics, \\ Medical University of Bialystok, 2c Mickiewicza Street, 15-233 Bialystok, Poland \\ ${ }^{4}$ Department of Physiology, Medical University of Bialystok, 2C Adama Mickiewicza Street, 15-022 Bialystok, Poland \\ ${ }^{5}$ Faculty of Rehabilitation, Józef Pitsudski University of Physical Education in Warsaw, Marymoncka 34, 00-968 Warsaw, Poland \\ ${ }^{6}$ Department of Kinesiology, Institute of Sport-National Research Institute, Trylogii 2, 01-982 Warsaw, Poland \\ ${ }^{7}$ Department of Biochemistry and Physiology, Faculty of Physical Education and Sport in Biała Podlaska, Józef Piłsudski University \\ of Physical Education in Warsaw, Akademicka 2, 21-500 Biała Podlaska, Poland
}

Correspondence should be addressed to Mateusz Maciejczyk; mat.maciejczyk@gmail.com

Received 4 October 2021; Revised 29 December 2021; Accepted 2 February 2022; Published 25 February 2022

Academic Editor: Przemko Tylzanowski

Copyright (c) 2022 Mateusz Maciejczyk et al. This is an open access article distributed under the Creative Commons Attribution License, which permits unrestricted use, distribution, and reproduction in any medium, provided the original work is properly cited.

Hypoxia is a recognized inducer of oxidative stress during prolonged physical activity. Nevertheless, previous studies have not systematically examined the effects of normoxia and hypoxia during acute physical exercise. The study is aimed at evaluating the relationship between enzymatic and nonenzymatic antioxidant barrier, total antioxidant/oxidant status, oxidative and nitrosative damage, inflammation, and lysosomal function in different acute exercise protocols under normoxia and hypoxia. Fifteen competitive athletes were recruited for the study. They were subjected to two types of acute cycling exercise with different intensities and durations: graded exercise until exhaustion (GE) and simulated $30 \mathrm{~km}$ individual time trial (TT). Both exercise protocols were performed under normoxic and hypoxic $\left(\mathrm{FiO}_{2}=16.5 \%\right)$ conditions. The number of subjects was determined based on our previous experiment, assuming the test power $=0.8$ and $\alpha=0.05$. We demonstrated enhanced enzymatic antioxidant systems during hypoxic exercise (GE: $\uparrow$ catalase (CAT), $\uparrow$ superoxide dismutase; TT: $\uparrow$ CAT) with a concomitant decrease in plasma reduced glutathione. In athletes exercising in hypoxia, redox status was shifted in favor of oxidation reactions (GE: $\uparrow$ total oxidant status, $\downarrow$ redox ratio), leading to increased oxidation/nitration of proteins (GE: $\uparrow$ advanced oxidation protein products (AOPP), $\uparrow$ ischemia-modified albumin, $\uparrow$ 3-nitrotyrosine, $\uparrow$ S-nitrosothiols; TT: $\uparrow$ AOPP) and lipids (GE: $\uparrow$ malondialdehyde). Concentrations of nitric oxide and its metabolites (peroxynitrite) were significantly higher in the plasma of hypoxic exercisers with an associated increase in inflammatory mediators (GE: $\uparrow$ myeloperoxidase, $\uparrow$ tumor necrosis factor-alpha) and lysosomal exoglycosidase activity (GE: $\uparrow \mathrm{N}$-acetyl- $\beta$-hexosaminidase, $\uparrow \beta$-glucuronidase). Our study indicates that even a single intensive exercise session disrupts the antioxidant barrier and leads to increased oxidative and nitrosative damage at the systemic level. High-intensity exercise until exhaustion (GE) alters redox homeostasis more than the less intense exercise (TT, near the anaerobic threshold) of longer duration $(20.2 \pm 1.9 \mathrm{~min}$ vs. $61.1 \pm 5.4 \mathrm{~min}-$ normoxia; $18.0 \pm 1.9 \mathrm{~min}$ vs. $63.7 \pm 3.0 \mathrm{~min}-$ hypoxia), while hypoxia significantly exacerbates oxidative stress, inflammation, and lysosomal dysfunction in athletic subjects. 


\section{Introduction}

An inevitable consequence of functioning under aerobic conditions is the production of reactive oxygen (ROS) and nitrogen species (RNS). ROS and RNS are typical byproducts of oxygen metabolism and important messengers in cellular signal processing. Under physiological conditions, ROS and RNS are involved in energy metabolism, erythropoiesis, muscle contraction, and other biochemical processes [1-3]. The signaling activity of free radicals is based on the modulation of several transcription factors, e.g., NF- $\kappa \mathrm{B}$ (nuclear factor kappa-light-chain-enhancer of activated $\mathrm{B}$ cells) and HIF-1 (hypoxia-inducible factor-1), which results in S-nitrosylation of proteins and induction of secondorder transmitter formation, as well as changes in cellular redox status [4-6]. However, ROS and RNS overproduction and/or insufficient antioxidant defense can cause redox imbalance, leading to cellular damage by oxidation and nitration. Such a state is defined as oxidative and nitrosative stress, which plays an essential role in many contemporary diseases, including metabolic $[7,8]$, neurodegenerative [9, $10]$, autoimmune $[11,12]$, and neoplastic disorders [13, 14]. Interestingly, factors inducing oxidative and nitrosative stress involve physical exercise [2, 15-17]. It was shown that overproduction of ROS/RNS occurs both during and after training $[2,15,16]$. A direct source of free radicals is the activity of mitochondrial enzymes and membrane oxidases (e.g., NADPH oxidase (NOX)), disturbances of ion homeostasis (especially iron and calcium ions), or changes in lysosomal function. The rate of ROS formation depends on the intensity and duration of exercise, the degree of training of the subjects, their age, sex, and diet $[2,15,16,18,19]$. It was shown that regular long-term aerobic exercise, especially at high intensity, is responsible for a significant increase in oxidative stress through intensified oxygen consumption [19-21]. Lipid peroxidation of muscle cells results in decreased fluidity and higher permeability of cellular membranes and enhanced oxidation of proteins and their tissue aggregation, as well as ROS-mediated DNA injury, causing an inflammatory response, delayed muscle soreness, and the release of intramuscular enzymes into the blood [15, 22, 23]. Nevertheless, little is known on redox homeostasis, nitrosative stress, and inflammatory response after acute physical intervention.

Nowadays, altitude/hypoxic training is becoming increasingly popular in sports [24-27]. Exposure to hypoxia leads to stimulation of HIF-1, which, apart from regulation of erythropoiesis and angiogenesis, is also a regulator of activity of glycolytic enzymes, mainly phosphofructokinase (PFK-1) [28, 29]. Therefore, improvements in aerobic and anaerobic capacity may occur. However, hypoxia and subsequent reoxygenation are also responsible for ROS/RNS overproduction, during prolonged exposure to altitude, as well as during intermittent hypoxic training [29-31]. This is caused by disruption of the mitochondrial respiratory chain, disturbances in arachidonic acid metabolism, or migration/activation of immune cells during regular physical activity $[24,25,30,31]$. Nevertheless, there is a lack of studies evaluating the relationship between antioxidant systems, oxidative and nitrosative cell damage, inflammation, and lysosomal function under normoxic and hypoxic conditions. We speculate that even acute physical exercise can induce oxidative stress and inflammation, and hypoxia can exacerbate these disorders. As interest in high-altitude sports grows, it is essential to understand the differences in redox homeostasis between various protocols of acute physical intervention. Previous studies have examined only a few aspects of redox homeostasis [30, 32, 33] and ultimately have not systematically studied the effects of normoxia and hypoxia during acute exercise. Therefore, the present study is aimed at evaluating the relationship between (1) enzymatic and nonenzymatic antioxidant barrier, (2) total antioxidant/ oxidant status, (3) oxidative and (4) nitrosative cell damage, (5) biomarkers of inflammation, and (6) lysosomal function in different protocols (different intensity and duration) performed under normoxic and hypoxic conditions.

\section{Materials and Methods}

2.1. Participants. The investigation conformed with the principles outlined in the Declaration of Helsinki and was approved by the Bioethics Committee of the Medical University of Bialystok (approval no. R-I-002/325/2019). All subjects gave their informed consent before their inclusion in the study.

Fifteen well-trained male competitive athletes (12 cyclists and 3 triathlonists) aged $25.4 \pm 8.4$ years, with BMI of $21.6 \pm 1.8 \mathrm{~kg} / \mathrm{m}^{2}$, body fat content of $9.2 \pm 2.1 \%$, and $\mathrm{VO}_{2} \mathrm{max}$ of $61.4 \pm 3.1 \mathrm{~mL} / \mathrm{kg} / \mathrm{min}$ were recruited for the study. Their average training experience was $6.3 \pm 2.0$ years. Only candidates with a valid medical certificate confirming the absence of contraindications to the practice of competitive sport activity were accepted.

2.2. Experimental Design. The subjects were tested on two occasions, separated by 14 days, in normoxic and hypoxic $\left(\mathrm{FiO}_{2}=16.5 \%\right.$, equivalent to $2,000 \mathrm{~m}$ asl $)$ conditions applied in random order. The tests were performed in a laboratory room equipped with a normobaric hypoxia system (AirZone 25, Air Sport, Poland) allowing to freely manipulate the oxygen concentration in the room air. Temperature $\left(19^{\circ} \mathrm{C}\right)$, humidity (50\%), and $\mathrm{CO}_{2}$ concentration (700-800 ppm) were controlled and held constant. The study participants were blinded to exercise conditions. The athletes were instructed to maintain their regular diet and supplementation throughout the experiment and avoid caffeine intake for $24 \mathrm{~h}$ preceding each test. All participants arrived at the camp one day before the start of each test series and consumed the same meals throughout their stay $(40 \mathrm{kcal} / \mathrm{kg} / \mathrm{d}$, $50 \%$ carbohydrates, $20 \%$ proteins, and $30 \%$ fats).

On the first day of each stay, two hours after a light breakfast, the subjects performed graded cycling exercise beginning with a workload of $120 \mathrm{~W}$, which was subsequently increased by $40 \mathrm{~W}$ every 3 minutes until volitional exhaustion. The total duration of exposure to hypoxia during this test was $\sim 35 \mathrm{~min}$. On the second day, following $24 \mathrm{~h}$ of rest and two hours after a light breakfast, the athletes performed a simulated $30 \mathrm{~km}$ individual time trial (TT) in a 
mountainous terrain. The TT was preceded by a $15 \mathrm{~min}$ warm-up, carried out according to the individual preferences of the athletes, under the same oxygen concentration as during the main exercise. The total duration of exposure to hypoxia during this test was $\sim 90 \mathrm{~min}$. Both tests were performed on subjects' personal bicycles connected to an electromagnetic bicycle trainer (Cyclus 2, RBM ElektronikAutomation $\mathrm{GmbH}$, Leipzig, Germany). During each test series, the athletes were allowed to consume water ad libitum. The oxygen saturation of arterial blood $\left(\mathrm{SpO}_{2}\right)$ and heart rate (HR) was measured using the WristOx2 pulse oximeter (Nonin Medical Inc., Plymouth, USA).

2.3. Blood Collection. Blood samples were taken from the antecubital vein into $4 \mathrm{~mL}$ EDTA tubes at three-time points: before the exercise, immediately after its completion, and following $30 \mathrm{~min}$ of rest. They were kept on ice until centrifugation at $375 \times \mathrm{g}$ for $10 \mathrm{~min}$ at $4^{\circ} \mathrm{C}$. Platelet-rich plasma was transferred to a fresh plastic tube, and the leukocyterich buffy coat was thoroughly removed. Separated erythrocytes were suspended in ice-cold PBS and centrifuged at $800 \times \mathrm{g}$ for $10 \mathrm{~min}$, and the upper layer and the remaining buffy coat were discarded. Red blood cells were then resuspended in PBS and flash-frozen in liquid nitrogen. Platelet-rich plasma was centrifuged at $2000 \times \mathrm{g}$ for $10 \mathrm{~min}$ to sediment platelets. The supernatant was then transferred to a fresh plastic tube and recentrifuged at $5000 \times \mathrm{g}$ for 10 minutes to obtain platelet-free plasma. All samples were stored at $-80^{\circ} \mathrm{C}$ until analysis.

2.4. Biochemical Assays. All reagents were of analytical grade and purchased (unless otherwise stated) from Sigma-Aldrich (Nümbrecht, Germany, or Saint Louis, MO, USA). Redox determinations were performed in duplicate assays: assessment of antioxidant enzymes in erythrocyte samples and assessment of nonenzymatic antioxidants, oxidative and nitrosative stress products, inflammatory mediators, and lysosomal enzymes in the plasma samples. The absorbance and fluorescence were determined using an Infinite M200 PRO multimode microplate reader (Tecan Group Ltd., Männedorf, Switzerland). The results were then standardized to $1 \mathrm{mg}$ of total protein content, as reported in several other publications [34-40]. The total protein level was evaluated with the bicinchoninic acid (BCA) method, using a commercial kit (Thermo Scientific PIERCE BCA Protein Assay (Rockford, IL, USA)), with bovine serum albumin (BSA) as a standard. Redox determinations were performed no more than two months after the samples were frozen.

2.5. Enzymatic Antioxidant Barrier. Catalase (CAT, E.C. 1.11.1.6) activity was measured with the method developed by Aebi [41], by evaluation of hydrogen peroxide decomposition, measured spectrophotometrically at the wavelength of $240 \mathrm{~nm}$. One unit of CAT was defined as the amount of the enzyme which is needed to decompose one nmol of hydrogen peroxide within 1 minute. The results are presented as $\mathrm{nmol} \mathrm{H}_{2} \mathrm{O}_{2} / \mathrm{min} / \mathrm{mg}$ protein.

The activity of glutathione peroxidase (GPx, E.C. 1.11.1.9) was determined using Paglia and Valentine's method [42] based on the conversion of NADPH (reduced nicotinamide adenine dinucleotide) to $\mathrm{NADP}^{+}$(nicotinamide adenine dinucleotide cation). The measurements were performed spectrophotometrically at $340 \mathrm{~nm}$. One unit of GPx was represented as the amount of the enzyme necessary to catalyze the oxidation of $1 \mu \mathrm{mol}$ of $\mathrm{NADPH}$ within 1 minute [43]. The results are presented as $\mathrm{mU} / \mathrm{mg}$ protein.

Glutathione reductase (GR, E.C. 1.8.1.7) activity was evaluated spectrophotometrically with the Mize and Langdon [44] method at the wavelength of $340 \mathrm{~nm}$. It was assumed that one unit of GR catalyzing oxidation of $1 \mu \mathrm{mol}$ of NADPH within 1 minute. The results are presented as $\mathrm{mU} / \mathrm{mg}$ protein.

The activity of superoxide dismutase (SOD, E.C. 1.15.1.1) was determined with the spectrophotometric method, according to Misra and Fredovich [45]. The absorbance changes accompanying adrenaline oxidation to adrenochrome were measured at the wavelength of $480 \mathrm{~nm}$. One SOD unit corresponds to the amount of enzyme reducing adrenaline oxidation by $50 \%$. The results are presented as $\mathrm{mU} / \mathrm{mg}$ protein.

2.6. Nonenzymatic Antioxidant Barrier. The uric acid (UA) concentration was measured spectrophotometrically at the wavelength of $490 \mathrm{~nm}$ using the commercial kit (QuantiChromTMUric Acid Assay Kit DIUA-250; BioAssay Systems, Hayward, CA, USA) according to the manufacturer's instructions. The results are presented as $\mu \mathrm{mol} / \mathrm{mg}$ protein.

The concentration of reduced (GSH) and oxidized (GSSG) glutathione was evaluated colorimetrically. The determination was based on the enzymatic reaction between NADPH, DTNB (5,5' -Dithiobis-(2-nitrobenzoic acid), and GR. In order to determine GSSG concentration, the samples were incubated with 2-vinylpiridine to inhibit glutathione oxidation after neutralization with $1 \mathrm{M}$ chlorhydrol triethanolamine to pH 6-7. The concentration of GSH was calculated as a difference in the levels of total glutathione and GSSG. The measurements were taken at the $412 \mathrm{~nm}$ wavelength [46, 47]. The results are presented as $\mu \mathrm{mol} / \mathrm{mg}$ protein.

Oxidation/reduction potential (redox ratio) was calculated based on the formula $=[\mathrm{GSH}]^{2} /[\mathrm{GSSG}][48]$.

2.7. Antioxidant Status. Total antioxidant capacity (TAC) was determined by the Erel's method [49]. 2,2-Azinobis (3ethylbenzene-thiazoline-6-sulfonate) (ABTS) was mixed with potassium persulfate and incubated at room temperature for 12 hours to obtain $\mathrm{ABTS}^{+}$. In the next step, $1 \mathrm{~mL}$ of $\mathrm{ABTS}^{+}$was added to $10 \mu \mathrm{L}$ of samples, and the absorbance was read $735 \mathrm{~nm}$ wavelength. Results of decolorization were linear with increasing Trolox concentrations. The results are presented as $\mu \mathrm{mol} / \mathrm{mg}$ protein.

Total oxidant status (TOS) was evaluated colorimetrically by Erel's method [50], using the oxidation reaction of $\mathrm{Fe}^{2+}$ to $\mathrm{Fe}^{3+}$ ions. $\mathrm{Fe}^{3+}$ ions were then detected using xylenol orange. The results are presented as nmol $\mathrm{H}_{2} \mathrm{O}_{2}$ equivalent/ mg protein.

The oxidative stress index (OSI) was calculated using the formula: OSI $=\left[\right.$ TOS, $\mu$ mol $\mathrm{H}_{2} \mathrm{O}_{2}$ equivalent/L[/[TAC, mmol Trolox/L] $\times 10[51,52]$. 
2.8. Oxidative Stress. The concentration of thiobarbituric acid reactive substances (TBARS) was measured colorimetrically using thiobarbituric acid (TBA) method. 1,1,3,3-Tetraethoxypropane was used as the standard, and determination was performed at $535 \mathrm{~nm}[53,54]$. The results are presented as $\mu \mathrm{mol} / \mathrm{mg}$ protein.

The spectrophotometric detection evaluated the concentration of advanced oxidation protein products (AOPP). Potassium iodide and acetic acid were added to the wells, and the absorbance was read immediately at $340 \mathrm{~nm}$ [55, 56]. The results are presented as $\mu \mathrm{mol} / \mathrm{mg}$ protein.

Ischemia modified albumin (IMA) concentration was determined colorimetrically at $470 \mathrm{~nm}$. The determination was based on the measurement of the exogenous cobalt $\left(\mathrm{Co}^{2+}\right)$ binding facility of human plasma albumin $[57,58]$. The results are presented as $\mu \mathrm{mol} / \mathrm{mg}$ protein.

2.9. Nitrosative Stress. Nitrate/nitrite (NOx) concentration was determined spectrofluorimetrically. Stable decomposition products of nitric oxide (NO) from the Griess reaction were evaluated by measuring absorbance at $543 \mathrm{~nm}$ wavelength [59]. The results are presented as $\mu \mathrm{mol} / \mathrm{mg}$ protein.

The peroxynitrite level was determined spectrophotometrically by measurement of the absorbance of nitrophenol at the wavelength of $320 \mathrm{~nm}$. The nitrophenol production resulted from the decomposition of peroxynitrite followed by nitration of glycyltyrosine and 4-hydroxyphenyloacetic acid (4-HPA) [60, 61]. The results are presented as $\mu \mathrm{mol} /$ $\mathrm{mg}$ protein.

3-Nitrotyrosine (3-NT) level was measured using the ELISA method. According to the manufacturer's instructions, a commercial kit (Nitrotyrosine ELISA; Immundiagnostik AG, Bensheim, Germany) was used. The results are presented as $\mu \mathrm{mol} / \mathrm{mg}$ protein.

S-Nitrosothiol concentration was measured spectrophotometrically based on the reaction of the $\mathrm{Cu}^{2+}$ ions with the Griess reagent [62]. The solution was shaken and incubated for 20 minutes, after which the absorbance was measured at $490 \mathrm{~nm}$ [63]. The results are presented as nmol/ mg protein.

2.10. Inflammation and Lysosomal Function. Myeloperoxidase (MPO, EC 1.11.2.2) activity was analyzed spectrophotometrically using sulfanilamide hexadecyl trimethylammonium, ortho-dianisidinedihydrochloride, and hydrogen peroxide $[37,64]$. The absorbance was measured at $450 \mathrm{~nm}$. The results are presented as $\mathrm{mU} / \mathrm{mg}$ protein.

The tumor necrosis factor-alpha (TNF- $\alpha$ ) level was determined by the ELISA method using a commercially available kit (EIAab Science Inc. Wuhan; Wuhan, China) according to the manufacturer's instructions. The results are presented as $\mathrm{pg} / \mathrm{mL}$.

The activity of $\mathrm{N}$-acetyl- $\beta$-hexosaminidase (HEX, EC 3.2.1.52) and $\beta$-glucuronidase (GLU, EC 3.2.1.31) was estimated colorimetrically at $405 \mathrm{~nm}$ using 4-nitrophenyl$\mathrm{N}$-acetyl- $\beta$-glucosaminide (HEX) and 4-nitrophenyl- $\beta$-Dglucuronide (GLU) as a substrate reaction $[65,66]$. The results are presented as $\mathrm{pKat} / \mathrm{mg}$ protein.
2.11. Statistical Analysis. Statistical analysis was performed using GraphPad Prism 8.4.3 for macOS (GraphPad Software, Inc. La Jolla, USA). The normality of the distribution was assessed using the Shapiro-Wilk test, while homogeneity of variance used the Levene test. For comparison of quantitative variables, the two-way analysis of variance (ANOVA) followed by the original FDR method of Benjamini and Hochberg was used. Multiplicity adjusted $p$ value was also calculated. The relationship between the assessed biomarkers was evaluated using the Pearson correlation coefficient. The statistical significance level was set at $p<0.05$.

The number of subjects was determined based on our previous experiment, assuming the test power $=0.8$ and $\alpha=0.05$ (online ClinCalc sample size calculator). Erythrocyte GSH-Px, plasma GSH, TAC, TBARS, AOPP, and peroxynitrite were used for calculations, and the minimum number of subjects should be 13 (in one group).

\section{Results}

3.1. Exercise Performance. The duration of the GE under normoxic conditions was $20.2 \pm 1.9 \mathrm{~min}$, and the maximal work rate amounted to $5.1 \pm 0.3 \mathrm{~W} / \mathrm{kg}$ of body weight. The $\mathrm{SpO}_{2}$ was $98.0 \pm 0.8$ and $91.9 \pm 3.0 \%$ at rest and at the end of the exercise, respectively. The heart rate at the point of exhaustion was $193 \pm 8 \mathrm{bpm}$. In hypoxia, the average duration of the exercise was $18.0 \pm 1.9 \mathrm{~min}$, whereas the maximal work rate was $4.6 \pm 0.4 \mathrm{~W} / \mathrm{kg}$. The $\mathrm{SpO}_{2}$ was $93.3 \pm 3.4$ and $84.3 \pm 5.4 \%$ at rest and at the point of exhaustion, respectively. The heart rate at the end of the exercise was $190 \pm 9 \mathrm{bpm}$.

The duration of the TT in normoxia was $61.1 \pm 5.4 \mathrm{~min}$, and the average work rate was $3.6 \pm 0.3 \mathrm{~W} / \mathrm{kg}$ of body weight. The $\mathrm{SpO}_{2}$ amounted to $97.8 \pm 2.0$ and $93.6 \pm 2.3 \%$ at rest and at the end of the exercise, respectively. The average heart rate was $176 \pm 9,177 \pm 8$, and $179 \pm 10 \mathrm{bpm}$ after 10,20 , and $30 \mathrm{~km}$ of the TT, respectively. Under hypoxic conditions, the TT lasted $63.7 \pm 3.0 \mathrm{~min}$, whereas the average work rate was $3.3 \pm 0.2 \mathrm{~W} / \mathrm{kg}$. The $\mathrm{SpO}_{2}$ was $93.3 \pm 3.8$ and $86.5 \pm 2.7 \%$ at rest and at the end of the TT, respectively. The mean heart rate was $174 \pm 11,176 \pm 13$, and $180 \pm 12 \mathrm{bpm}$ after 10,20 , and $30 \mathrm{~km}$ of the TT, respectively.

3.2. Enzymatic Antioxidant Barrier. In normoxia, after the (GE) activity of glutathione reductase (GR) increased by $9 \%(p=0.0464)$, while after 30 minutes of resting, the activity of catalase (CAT) rose $25.4 \%(p=0.0003)$, and the activity of glutathione peroxidise (GPx) decreased by $13 \%$ $(p=0.0081)$, all comparing to the preexercise activity. In hypoxia, the postexercise activity of CAT and superoxide dismutase (SOD) was consecutively $28 \%(p=0.0002)$ and $59.8 \%(p<0.0001)$ greater than preexercise. After resting, the activity of CAT was $41.6 \%$ higher $(p<0.0001)$ than before the GE, and SOD activity was $33.9 \%$ lower $(p<0.0001)$ comparing to the evaluation performed immediately after exercise. When comparing the enzymatic activity in groups exercising hypoxia to those exercising normoxia, the CAT activity was $24 \%$ higher $(p=0.0088)$ before the GE. In postexercise measurement, the activity of CAT 
was $6 \%$ higher $(p<0.0001)$, the activity of GPx was $12.1 \%$ lower $(p=0.0175)$, and the activity of SOD was $71.7 \%$ greater $(p<0.0001)$. Moreover, the activity of CAT after resting was $41.6 \%$ higher $(p<0.0001)$ in hypoxia (Figure $1, \mathrm{GE})$.

After $30 \mathrm{~km}$ TT in normoxia, the activity of CAT and SOD after the exercise rose $18.8 \%(p=0.0386)$ and $17.1 \%$ $(p=0.046)$ consecutively, and after resting for 30 minutes, the activity of GPx and SOD increased by $15.2 \%$ $(p<0.0001)$ and $22.3 \%(p=0.01)$, respectively, all comparing to the activity before exercising. If compared to the postexercise value, after resting, the activity of GPx decreased by $24.4 \%(p=0.0009)$. After the exercise in hypoxia, there was a significant increase in the activity of CAT $(17.2 \% ; p=0.0242)$ and SOD $(47.9 \% ; p<0.0001)$. Furthermore, the activity of SOD after resting was $24.4 \%$ lower $(p=0.0009)$ than after the exercise. Before TT, the activity of CAT in hypoxia was $18.9 \%$ $(p<0.0001)$ greater than in normoxia and $17.4 \%(p=0.0233)$ greater after the exercise, while the postexercise SOD activity was $10.5 \%(p=0.003)$ lower in hypoxia than in normoxia. Evaluation taken 30 minutes after the end of TT revealed that in hypoxia, the activity of GPX and SOD was significantly lower than in normoxia-18.7\% $(p<0.0001)$ and $19.9 \%(p=0.0051)$, respectively (Figure 1, TT).

3.3. Nonenzymatic Antioxidant Barrier. There were no significant changes in concentration of uric acid (UA), reduced (GSH), and oxidized (GSSG) glutathione or value of redox ratio in normoxia after GE compared to those values before exercise. However, after 30 minutes rest, the concentration of UA increased by $18.7 \%(p=0.0058)$, while concentration of GSH and redox ratio lessened by $11.9 \%(p=0.0031)$ and $24.8 \%$ ( $p=0.0017$ ) consecutively, comparing to preexercise values. Redox ratio decreased also in comparison to postexercise value $(18 \%, p=0.0343)$. In hypoxia, comparing to the measurements taken before exercise, immediately after GE, concentration of UA increased by $23.6 \%(p=0.0006)$, and concentration of GSH and redox ratio decreased by $18 \%$ $(p=0.0002)$ and $31.1 \%(p=0.0053)$ consecutively after the exercise. After 30 minutes of resting, redox ratio was $33.5 \%$ lower $(p=0.0028)$. Moreover, concentration of GSH and redox ratio was significantly lower in hypoxia than in normoxia both before (GSH 15\%, $p=0.0002$; redox ratio $29.3 \%, p<0.0001$ ) and after (GSH 30\%, $p<0.0001$; redox ratio $51.3 \%, p<0.0001) \mathrm{GE}$, as well as after 30 minutes rest (GSH 19.7\%, $p<0.0001$; redox ratio $37.4 \%, p=0.0004$ ) (Figure 2, GE).

In normoxia, the concentration of GSH and redox ratio declined significantly after $30 \mathrm{~km}$ time trial-19\% $(p<0.0001)$ and $31.6 \%(p<0.0001)$, respectively. Thirty minutes after finishing the TT, UA concentration raised by $18.8 \%(p=0.0143)$, and concentration of $\mathrm{GSH}(13 \%, p=0.0048)$ and redox ratio (25.8\%, $p=0.0009)$ decreased significantly compared to the values observed before conducting the time trial, while the GSSG concentration increased by $7.79 \%(p=0.0366)$ comparing to the measurement taken immediately after the exercise. In hypoxia, $30 \mathrm{~km}$ time trial affected significantly the content of UA (increased by 22.3\%, $p=0.0018$ ), GSH (decreased by $35 \%, p<0.0001$ ), and redox ratio (decreased by $55 \%$, $p<0.0001)$. After resting, there was a significant decrease in
GSH concentration $(27.5 \%, p<0.0001)$ and redox ratio ( $48.8 \%, p<0.0001)$ in comparison to those before TT, while GSSG content was $7.8 \%$ higher $(p=0.038)$ than right after the exercise. Moreover, postexercise content of UA was $27 \%$ greater $(p=0.0003)$ in hypoxia than in normoxia, while the concentration of GSH and redox ratio was significantly lower in hypoxia-24.2\% $(p<0.0001)$ and $39.7 \%(p=0.0005)$, respectively. After 30 minutes of resting, GSH content and redox ratio were $20.9 \%(p=0.0001)$ and $36.8 \%(p<0.0001)$ lower in hypoxia than in normoxia (Figure 2, TT).

3.4. Antioxidant Status. Total oxidant status (TOS) was raised by graded exercise until exhaustion in normoxia by $31.9 \%$ $(p=0.0485)$, while total antioxidant capacity (TAC) and oxidative stress index (OSI) were not affected. Moreover, after 30 minutes of resting, TOS increased by $51.9 \%(p=0.0016)$, and OSI increased by $55.8 \%(p=0.0023)$ comparing to the preexercise. In hypoxia, both TAC and TOS were elevated after exercising-by $20.8 \% \quad(p=0.0025)$ and $29.7 \%$ $(p=0.0228)$, respectively. There were also significant rises of all described measurements after 30 minutes of rest in relation to the values observed before the exercise (TAC-13.6\%, $p=0.044$; TOS $-56.5 \%, p<0.0001$; OSI-37.1\%, $p=0.0276)$. TOS was also $20.6 \%$ higher $(p=0.0399)$ after resting than immediately after GE. Furthermore, postexercise TAC was $26.2 \%$ greater $(p=0.0003)$ in hypoxia than in normoxia, whereas both TAC and TOS values after resting were higher in hypoxia as well $(26.4 \%, p=0.0442 ; 28 \%, p=0.009$, respectively) (Figure 3, GE).

In normoxia, total antioxidant capacity was increased by $30 \mathrm{~km}$ time trial by $34.8 \%(p=0.0023)$ while oxidative stress index was elevated by $39.7 \%(p=0.0021)$. After resting, TAC was raised by $16.9 \%(p=0.0006)$ compared to preexercise values and by $19.9 \%(p=0.0001)$ compared to postexercise measurement. OSI was $28.4 \%(p=0.0021)$ lower after resting than immediately after TT. Hypoxia did not affect postexercise markers' values, but resting for 30 minutes led to $12.6 \%$ growth $(p=0.0104)$ comparing to the preexercise analysis. There were no significant differences between preexercise values comparing normoxia and hypoxia, although postexercise TAC was $10.3 \%$ higher $(p=0.0392)$ in hypoxia than in normoxia (Figure 3, TT).

3.5. Oxidative Stress. Graded exercise until exhaustion in normoxia did not influence oxidative stress marker concentration assessed directly after exercise. However, there were significant changes in TBARS $(24 \%$ increase compared to preexercise value, $p=0.0017$ ) and ischemia modified protein (IMA) (15.9\% increase compared to postexercise value, $p=0.0121)$ contents when measured after 30 minutes of rest. In hypoxia, TBARS concentration was elevated by $25.8 \%$ $(p=0.0002)$, and advanced oxidation protein product (AOPP) content was increased by $18.8 \%(p<0.0001)$ immediately after exercise. After the rest, the significant increase of the concentration of all evaluated substances was observed-TBARS by $42.2 \%(p<0.0001)$, AOPP by $43.8 \%(p<0.0001)$, and IMA by $27.6 \%(p<0.0001)$ comparing to the values before GE and TBARS by $13 \%(0.0141)$, AOPP by $21 \%(p<0.0001)$, and IMA by $17.2 \%(p=0.0003)$ comparing to the values after GE. 
GE

CAT erythrocytes

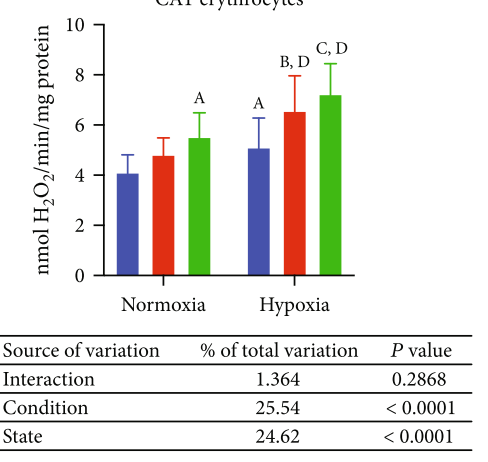

GPx erythrocytes

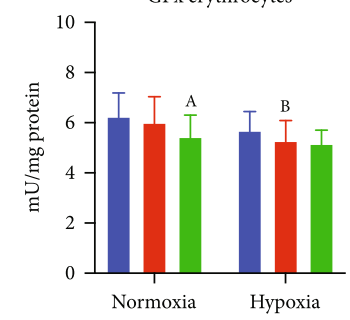

\begin{tabular}{lcc}
\hline Source of variation & \% of total variation & $P$ value \\
\hline Interaction & 1.076 & 0.5553 \\
\hline Condition & 8.150 & 0.0035 \\
\hline State & 9.016 & 0.0090 \\
\hline
\end{tabular}

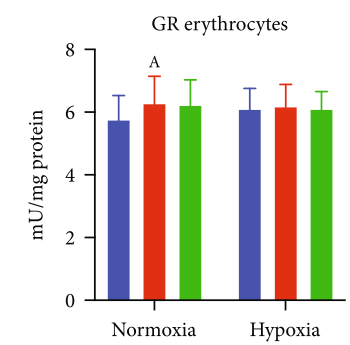

\begin{tabular}{lcc}
\hline Source of variation & $\%$ of total variation & $P$ value \\
\hline Interaction & 2.197 & 0.3559 \\
\hline Condition & 0.05875 & 0.8137 \\
\hline State & 3.140 & 0.2301 \\
\hline
\end{tabular}

State

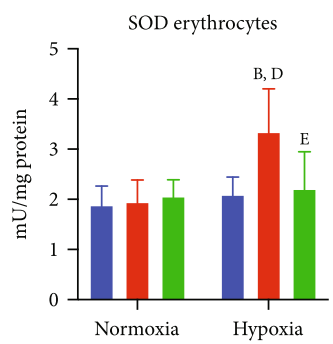

\begin{tabular}{lcc}
\hline Source of variation & \% of total variation & $P$ value \\
\hline Interaction & 15.29 & $<0.0001$ \\
\hline Condition & 15.81 & $<0.0001$ \\
\hline State & 14.68 & $<0.0001$ \\
\hline
\end{tabular}

Pre

Post

$30 \mathrm{~min}$
TT

CAT erythrocytes

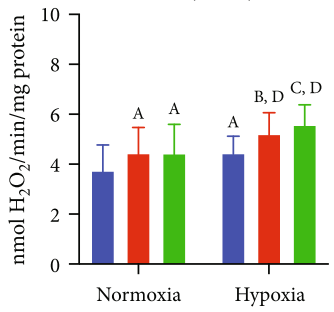

Source of variation $\%$ of total variation $\quad P$ value

Interaction $\quad 0.7842 \quad 0.6065$

\begin{tabular}{lcc}
\hline Condition & 16.02 & $<0.0001$ \\
\hline State & 13.03 & 0.0005
\end{tabular}

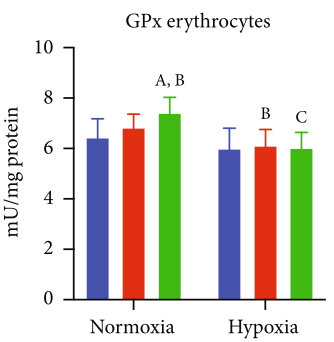

\begin{tabular}{lcc}
\hline Source of variation & $\%$ of total variation & $P$ value \\
\hline Interaction & 5.931 & 0.0157 \\
\hline Condition & 26.56 & $<0.0001$ \\
\hline State & 6.220 & 0.0129
\end{tabular}

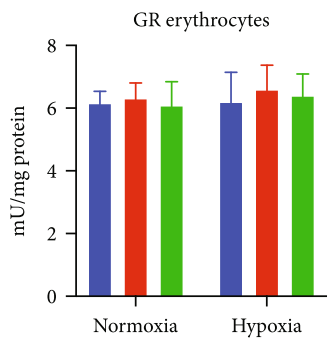

\begin{tabular}{lcc}
\hline Source of variation & \% of total variation & $P$ value \\
\hline Interaction & 0.7758 & 0.6913 \\
\hline Condition & 2.276 & 0.1437 \\
\hline State & 2.785 & 0.2694 \\
\hline
\end{tabular}

SOD erythrocytes

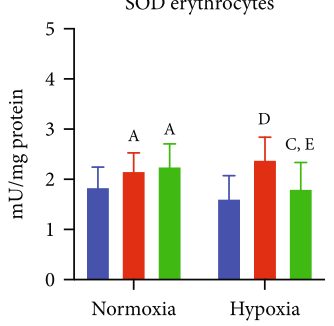

\begin{tabular}{lcc}
\hline Source of variation & $\%$ of total variation & $P$ value \\
\hline Interaction & 7.662 & 0.0099 \\
\hline Condition & 2.183 & 0.0996 \\
\hline State & 19.19 & $<0.0001$ \\
\hline
\end{tabular}

Pre
Post
$30 \mathrm{~min}$

FIGURE 1: Effect of graded exercise until exhaustion (GE) and $30 \mathrm{~km}$ time trial (TT) on the enzymatic antioxidant barrier in normoxia and hypoxia. CAT: catalase; GPx: glutathione peroxidase; GR: glutathione reductase; SOD: superoxide dismutase. a, $p<0.05$ vs. the value before exercise in normoxia; b, $p<0.05$ vs. the value after the exercise in normoxia; $c, p<0.05$ vs. the value after the exercise and 30 min of rest in normoxia; $\mathrm{d}, p<0.05$ vs. the value after the exercise in hypoxia; e, $p<0.05$ vs. the value after the exercise in hypoxia; $\mathrm{f}, p<0.05$ vs. the value after the exercise $30 \mathrm{~min}$ of rest in hypoxia. 

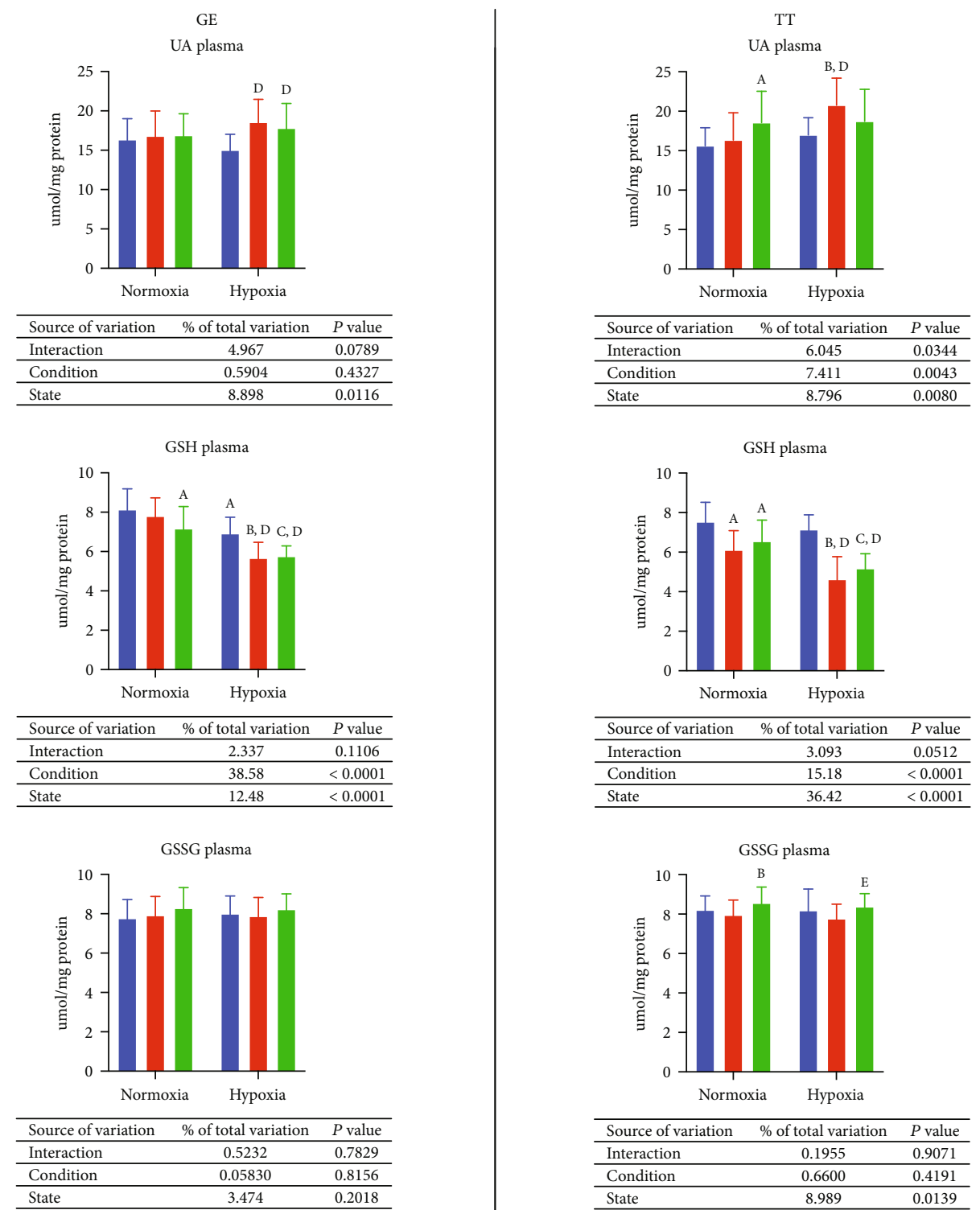

\begin{tabular}{lcc}
\hline Source of variation & \% of total variation & $P$ value \\
\hline Interaction & 0.1955 & 0.9071 \\
\hline Condition & 0.6600 & 0.4191 \\
\hline State & 8.989 & 0.0139 \\
\hline
\end{tabular}
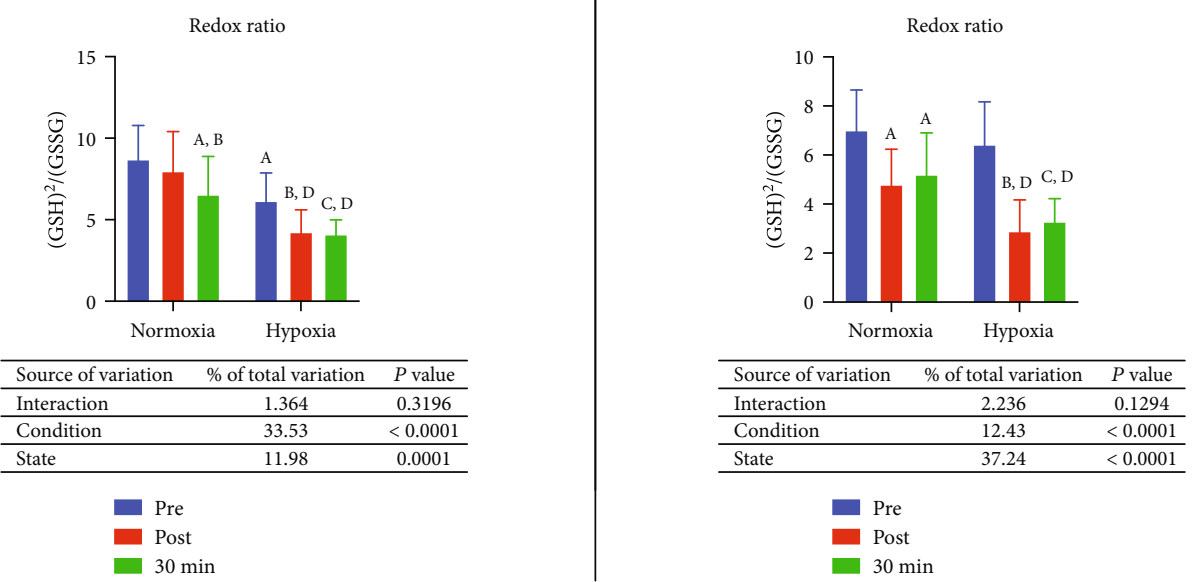

FIgURE 2: Effect of graded exercise until exhaustion (GE) and $30 \mathrm{~km}$ time trial (TT) on the nonenzymatic antioxidant barrier in normoxia and hypoxia. GSH: reduced glutathione; GSSG: oxidized glutathione; UA: uric acid. $a, p<0.05$ vs. the value before exercise in normoxia; $b$, $p<0.05$ vs. the value after the exercise in normoxia; $c, p<0.05$ vs. the value after the exercise and 30 min of rest in normoxia; $\mathrm{d}$, $p<0.05$ vs. the value after the exercise in hypoxia; e, $p<0.05$ vs. the value after the exercise in hypoxia; $\mathrm{f}, p<0.05$ vs. the value after the exercise 30 min of rest in hypoxia. 
GE

TAC plasma

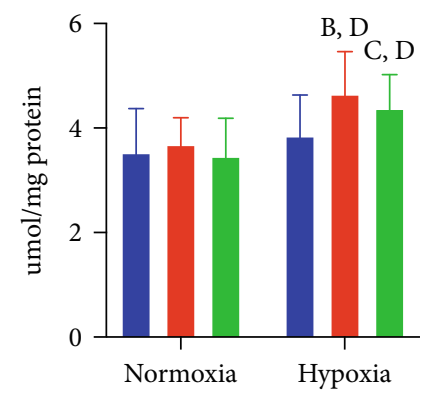

\begin{tabular}{lcc}
\hline Source of variation & \% of total variation & $P$ value \\
\hline Interaction & 3.093 & 0.1504 \\
\hline Condition & 19.45 & $<0.0001$ \\
\hline State & 5.508 & 0.0362 \\
\hline
\end{tabular}

TOS plasma

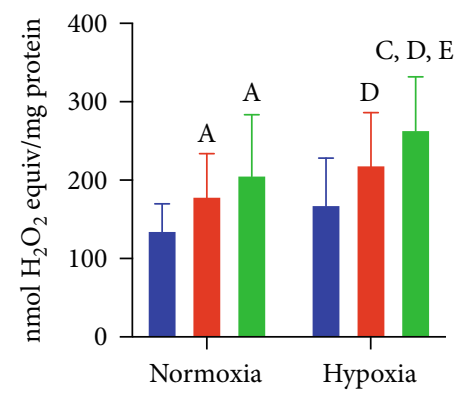

\begin{tabular}{lcc}
\hline Source of variation & \% of total variation & $P$ value \\
\hline Interaction & 0.5323 & 0.7042 \\
\hline Condition & 9.144 & 0.0008 \\
\hline State & 22.28 & $<0.0001$ \\
\hline
\end{tabular}

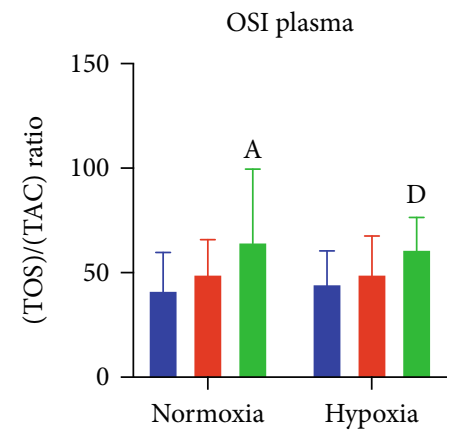

\begin{tabular}{lcc}
\hline Source of variation & $\%$ of total variation & $P$ value \\
\hline Interaction & 0.3778 & 0.8196 \\
\hline Condition & 0.0009351 & 0.9750 \\
\hline State & 14.32 & 0.0009 \\
\hline
\end{tabular}

Pre
Post
$30 \mathrm{~min}$

TT

TAC plasma

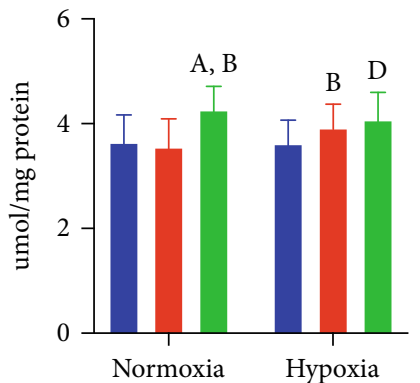

\begin{tabular}{lcc}
\hline Source of variation & $\%$ of total variation & $P$ value \\
\hline Interaction & 4.611 & 0.0730 \\
\hline Condition & 0.1936 & 0.6355 \\
\hline State & 18.19 & $<0.0001$ \\
\hline
\end{tabular}

TOS plasma

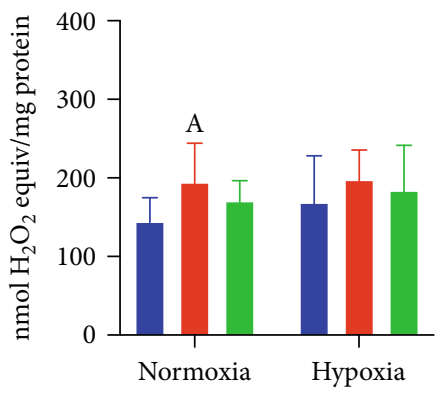

\begin{tabular}{lcc}
\hline Source of variation & $\%$ of total variation & $P$ value \\
\hline Interaction & 0.8306 & 0.6471 \\
\hline Condition & 2.078 & 0.1426 \\
\hline State & 11.63 & 0.0032 \\
\hline
\end{tabular}

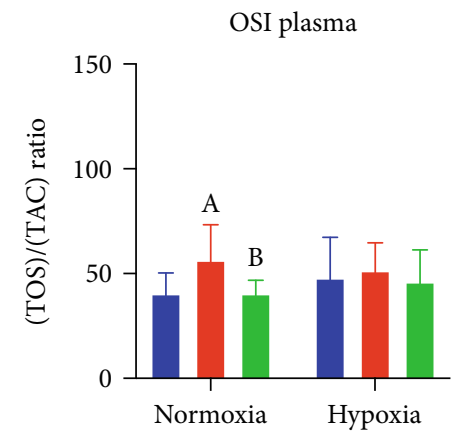

\begin{tabular}{|c|c|c|}
\hline Source of variation & $\%$ of total variation & $P$ value \\
\hline Interaction & 3.352 & 0.1767 \\
\hline Condition & 0.8060 & 0.3591 \\
\hline State & 10.48 & 0.0054 \\
\hline
\end{tabular}

FIGURE 3: Effect of graded exercise until exhaustion (GE) and $30 \mathrm{~km}$ time trial (TT) on antioxidant status in normoxia and hypoxia. OSI: oxidative stress index; TAC: total antioxidant capacity; TOS: total oxidant status. a, $p<0.05$ vs. the value before exercise in normoxia; $b$, $p<0.05$ vs. the value after the exercise in normoxia; $c, p<0.05$ vs. the value after the exercise and 30 min of rest in normoxia; $d, p<0.05$ vs. the value after the exercise in hypoxia; e, $p<0.05$ vs. the value after the exercise in hypoxia; $\mathrm{f}, p<0.05$ vs. the value after the exercise 30 min of rest in hypoxia. 
There were also no differences between preexercise concentrations in normoxia and hypoxia, while contents of all described substances were significantly higher in hypoxia than in normoxia after the GE-TBARS 29.4\% $(p<0.0001)$, AOPP $16.5 \%$ $(p=0.0032)$, and IMA $20.1 \%(p=0.0016)$-and after 30 minutes of resting-TBARS 29.7\% $(p<0.0001)$, AOPP $21 \%$ $(p<0.0001)$, and IMA $21.5 \%(p=0.0001)$ (Figure $4, \mathrm{GE})$.

After $30 \mathrm{~km}$ time trial in normoxia, the concentration of TBARS was increased by $21.5 \%(p=0.0034)$, and the content of AOPP was $12.9 \%(p=0.0401)$ higher. After 30 minutes of rest, the TBARS concentration was elevated by $16.1 \%(p=0.0267)$. In hypoxia, all postexercise oxidative stress markers' concentrations were elevated-TBARS by $42.7 \%(p<0.0001)$, AOPP by $49 \%(p<0.0001)$, and IMA by $19.4 \%(p=0.0101)$. Directly after the exercise, but after 30 minutes, the content of TBARS decreased by $11.5 \%$ $(p=0.0328)$. There were no differences between preexercise values in hypoxia and normoxia. The concentration of AOPP after TT in hypoxia was $24.2 \%$ greater $(p<0.0001)$ than in normoxia. After the rest, the contents of AOPP and IMA were also higher in hypoxia-39\% $(p<0.0001)$ and $15.7 \%(p=0.0407)$ consecutively (Figure 4, TT).

3.6. Nitrosative Stress. Besides $29.8 \%$ increase $(p=0.0014)$ in peroxynitrite level after 30 minutes of resting in relation to the pre-GE value and $18.8 \%$ decrease $(p=0.0291)$ in $\mathrm{S}$-nitrosothiol concentration after the rest compared to the measurement conducted directly after exercise, there was no other influence of GE in normoxia on nitrosative stress markers. In hypoxia, the 3-nitrotyrosine (3-NT) level was elevated by $15.9 \%(p=0.0223)$ after the exercise. After resting, levels of peroxynitrite and 3-NT and concentration of S-nitrosothiols increased by $15.6 \% \quad(p=0.0397), 41.1 \%$ $(p<0.0001)$, and $31.2 \%(p=0.0034)$, respectively, in comparison to the preexercise evaluation. Moreover, 3-NT level and S-nitrosothiol content were greater after 30 minutes of resting than immediately after exercise $(21.8 \%, p=0.0004$; $29 \%, p=0.0055$ consecutively). Comparing the group exercising in hypoxia to the group exercising in normoxia-in hypoxia, before exercise, the content of $\mathrm{NO}_{\mathrm{x}}$ was $20.2 \%$ higher $(p=0.0144)$, and the level of peroxynitrite was $21.1 \%$ greater $(p=0.0219)$. In comparison, after exercise, the $\mathrm{NO}_{\mathrm{x}}$ concentration and peroxynitrite level were $20.3 \%$ $(p=0.007)$ and $16.4 \%(p=0.0393)$ higher, and S-nitrosothiol concentration was $17.3 \%$ lower $(p=0.044)$. Furthermore, 30 minutes after finishing the exercise, $\mathrm{NO}_{\mathrm{x}}$ concentration, 3-NT level, and S-nitrosothiol content were also significantly higher in hypoxia-18.5\% $(p=0.0133), 25.4 \% \quad(p<0.0001)$, and $31.4 \%(p=0.0055)$, respectively (Figure 5, GE).

After a $30 \mathrm{~km} \mathrm{TT}$ in normoxia, the only significant change was $16.4 \%(p=0.0083)$ increase in peroxynitrite level. In hypoxia, the level of peroxynitrite rose $13.5 \%$ $(p=0.0252)$ after the exercise, while the level of $3-\mathrm{NT}$ increased by $13.1 \%(p=0.0193)$ after 30 minutes of rest, both comparing to the preexercise levels. Moreover, before the exercise, the concentration of $3-\mathrm{NT}$ was $12.7 \%$ higher $(p=0.0228)$ in hypoxia than normoxia. No other significant changes were observed (Figure 5, TT).
3.7. Inflammation and Lysosomal Function. After graded exercise until exhaustion in normoxia, there were no significant changes in the activity of myeloperoxidase (MPO), level of tumor necrosis factor-alpha (TNF- $\alpha$ ), or the activity of $\mathrm{N}$-acetyl- $\beta$-hexosaminidase (HEX) and $\beta$-glucuronidase (GLU). After 30 minutes of resting, level of TNF- $\alpha$ and the activity of GLU increased by $36.6 \%(p=0.0279)$ and $33.3 \%$ $(p=0.0322)$ comparing to preexercise, and the level of TNF- $\alpha$ rose $35 \%(p=0.033)$ comparing to postexercise value as well. In hypoxia, the activity of all examined enzymes, as well as the level of TNF- $\alpha$, increased after resting comparing to the measurement taken before exercise (MPO-52.4\%, $\quad p=0.0002 ; \quad$ TNF- $\alpha-71 \%, \quad p<0.0001$; HEX-47.7\%, $p<0.0001$; GLU-105.4\%, $p<0.0001)$. The level of TNF- $\alpha$ and activity of HEX and GLU were significantly higher after rest also comparing to the assessment performed directly after exercise-43.9\% $(p=0.0014)$, $47.7 \%(p<0.0001)$, and $84.7 \%(p<0.0001)$, respectively. No significant differences between inflammation and lysosomal function markers between values in normoxia and hypoxia were observed in measurements performed before and after GE. However, after 30 minutes, activity of all investigated enzymes and level of TNF- $\alpha$ were higher in hypoxia than in normoxia-MPO 34.4\% $(p=0.005)$, TNF- $\alpha$ 28.3\% $(p=0.0161)$, HEX $46 \% \quad(p<0.0001)$, and GLU 34.9\% ( $p=0.0031)$ (Figure 6, GE).

After $30 \mathrm{~km}$ TT in normoxia, the activity of GLU increased by $29.8 \%(p=0.038)$ considering pre-TT values. In hypoxia, the level of TNF- $\alpha$ raised by $38.3 \%(p=0.0109)$ subsequently to the exercise, while after 30 minutes, the activity of GLU raised by $6.4 \%(p=0.0012)$ comparing to the activity before exercise and by $9 \%(p<0.0001)$ comparing to the activity directly after exercise, and the activity of HEX increased by $17.2 \%(p=0.043)$ in relation to postexercise measurement. Comparing exercising in hypoxia to exercising in normoxia, the preexercise GLU activity in hypoxia was $31.7 \%$ $(p=0.0279)$ higher, while the postexercise activity of MPO was $33.6 \%(p=0.454)$ greater too. After resting, the activity of GLU was also $7.2 \%$ higher $(p=0.0002)$ in hypoxia (Figure 6, TT).

3.8. Correlations. The results of correlation analysis are shown in Figure 7. Of particular note is the negative correlation between GSH and TOS levels $(r=-0.465 ; p=0.001)$ and the positive correlation between peroxynitrite and TOS $(r=0.458 ; p=0.001)$ in the GE group in normoxic conditions. In the GE group in hypoxia, AOPP levels correlated positively with 3 -NT content $(r=0.571 ; p<0.0001)$ and GLU activity $(r=0.62 ; p<0.0001)$, whereas IMA levels correlated with 3 -NT $(r=0.55 ; p<0.0001)$ and GLU $(r=0.487$; $p<0.0001)$. Interestingly, UA concentration was also correlated negatively with WRmax $(r=-0.326 ; p=0.029)$. In the TT group in normoxia, GSH concentration $(r=-0.496$; $p<0.0001)$ and redox ratio $(r=-0.496 ; p=0.001)$ correlated negatively with CAT activity, whereas in hypoxia, UA concentration correlated positively with SOD activity $(r=0.487 ; p=0.013)$, and GSH correlated negatively with TBARS $(r=-0.486 ; p<0.0001)$ and AOPP level $(r=-0.605$; $p=0.0001)$. Similarly, redox ratio correlated negatively with 
GE

TBARS plasma

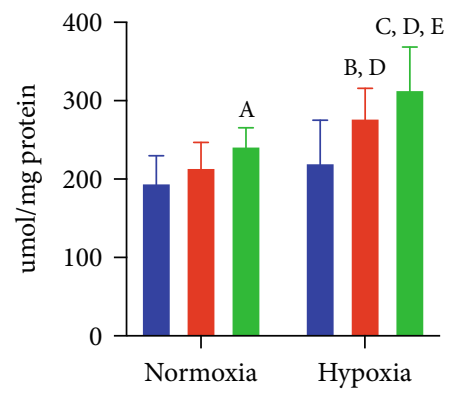

\begin{tabular}{lcc}
\hline Source of variation & \% of total variation & $P$ value \\
\hline Interaction & 3.142 & 0.0609 \\
\hline Condition & 22.35 & $<0.0001$ \\
\hline State & 25.54 & $<0.0001$ \\
\hline
\end{tabular}

AOPP plasma

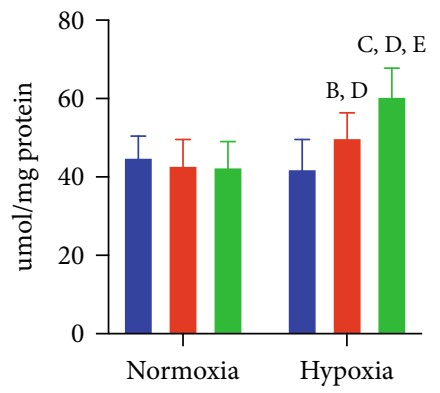

\begin{tabular}{lcc}
\hline Source of variation & \% of total variation & $P$ value \\
\hline Interaction & 21.77 & $<0.0001$ \\
\hline Condition & 16.30 & $<0.0001$ \\
\hline State & 12.97 & $<0.0001$ \\
\hline
\end{tabular}

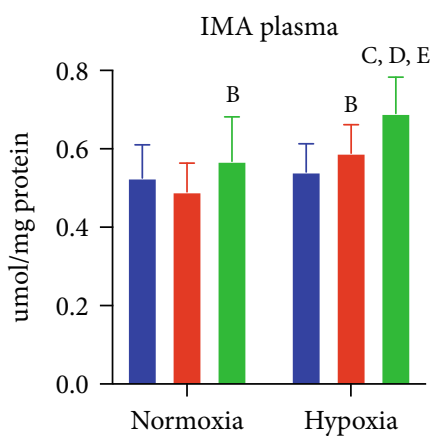

\begin{tabular}{|c|c|c|}
\hline Source of variation & $\%$ of total variation & $P$ value \\
\hline Interaction & 4.750 & 0.0388 \\
\hline Condition & 14.21 & $<0.0001$ \\
\hline State & 17.61 & $<0.0001$ \\
\hline
\end{tabular}

TT

TBARS plasma

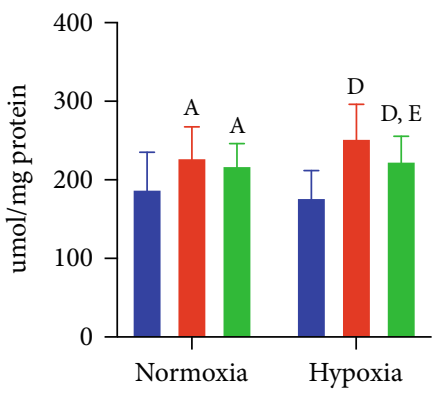

\begin{tabular}{lcc}
\hline Source of variation & \% of total variation & $P$ value \\
\hline Interaction & 2.608 & 0.1825 \\
\hline Condition & 0.5160 & 0.4097 \\
\hline State & 29.18 & $<0.0001$ \\
\hline
\end{tabular}

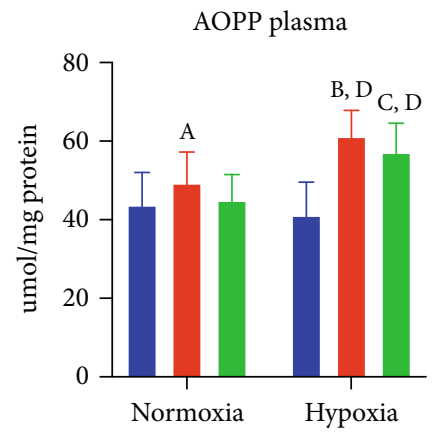

\begin{tabular}{lcc}
\hline Source of variation & $\%$ of total variation & $P$ value \\
\hline Interaction & 11.03 & 0.0001 \\
\hline Condition & 11.91 & $<0.0001$ \\
\hline State & 26.52 & $<0.0001$ \\
\hline
\end{tabular}

IMA plasma

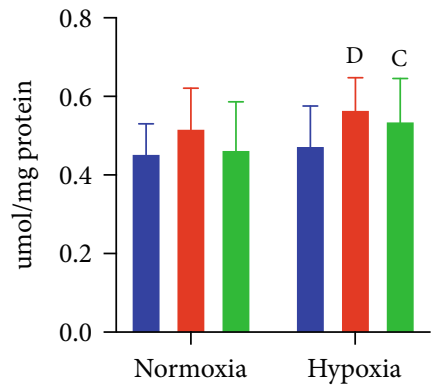

\begin{tabular}{|c|c|c|}
\hline Source of variation & $\%$ of total variation & $P$ value \\
\hline Interaction & 1.056 & 0.5720 \\
\hline Condition & 5.075 & 0.0223 \\
\hline State & 9.350 & 0.0089 \\
\hline
\end{tabular}

FIgURE 4: Effect on graded exercise until exhaustion (GE) and $30 \mathrm{~km}$ time trial (TT) on oxidative stress in normoxia and hypoxia. AOPP: advanced oxidation protein products; IMA: ischemia modified albumin; TBARS: thiobarbituric acid reactive substances. a, $p<0.05$ vs. the value before exercise in normoxia; $b, p<0.05$ vs. the value after the exercise in normoxia; $c, p<0.05$ vs. the value after the exercise and 30 min of rest in normoxia; $\mathrm{d}, p<0.05$ vs. the value after the exercise in hypoxia; e, $p<0.05$ vs. the value after the exercise in hypoxia; $\mathrm{f}$, $p<0.05$ vs. the value after the exercise $30 \mathrm{~min}$ of rest in hypoxia. 

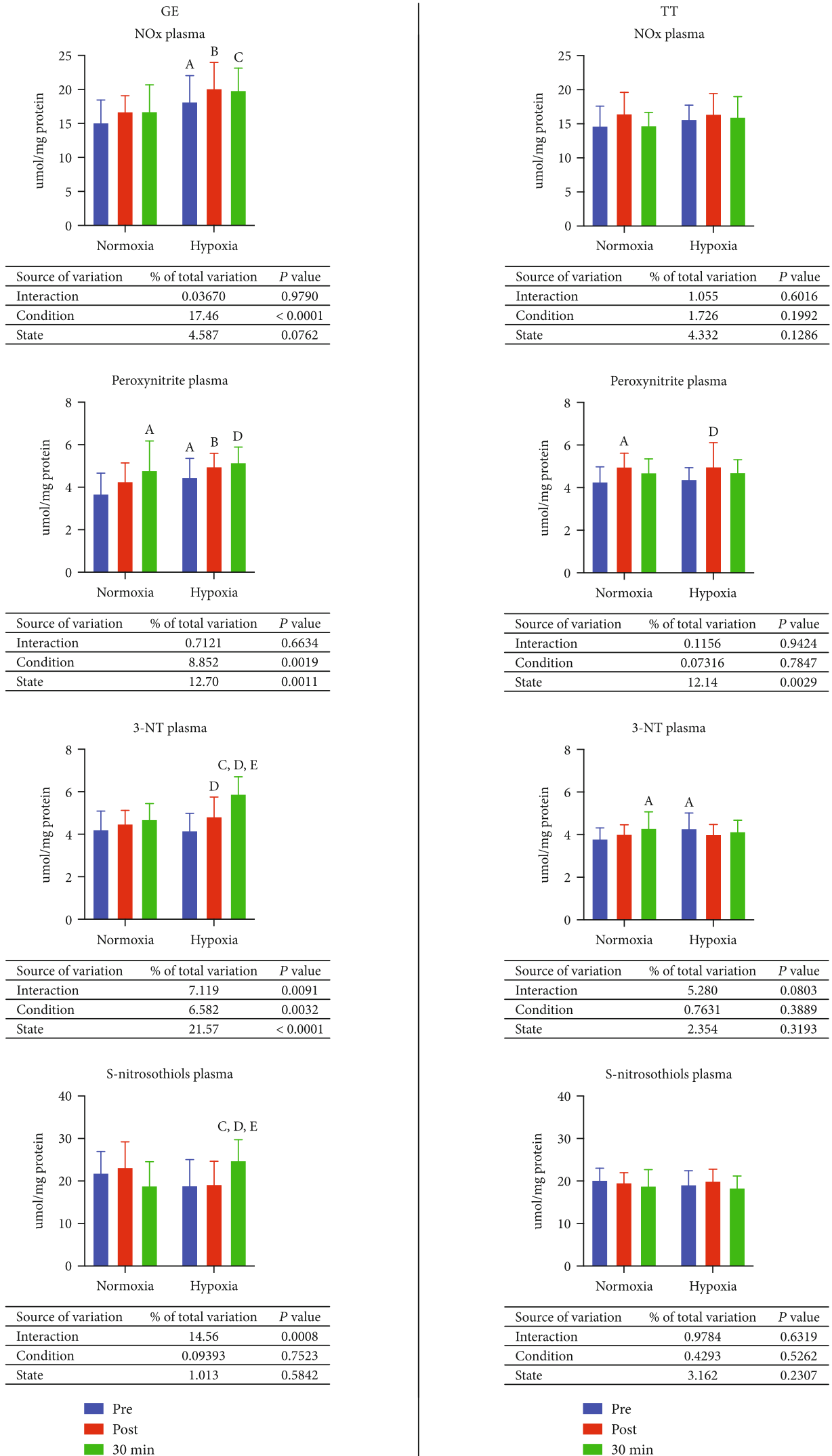

Figure 5: Effect on graded exercise until exhaustion (GE) and $30 \mathrm{~km}$ time trial (TT) on nitrosative stress in normoxia and hypoxia. 3-NT: 3-nitrotyrosine; $\mathrm{NO}_{\mathrm{x}}$ : nitrate/nitrite. a, $p<0.05$ vs. the value before exercise in normoxia; $\mathrm{b}, p<0.05$ vs. the value after the exercise in normoxia; $c, p<0.05$ vs. the value after the exercise and $30 \mathrm{~min}$ of rest in normoxia; $\mathrm{d}, p<0.05$ vs. the value after the exercise in hypoxia; e, $p<0.05$ vs. the value after the exercise in hypoxia; $\mathrm{f}, p<0.05$ vs. the value after the exercise 30 min of rest in hypoxia. 


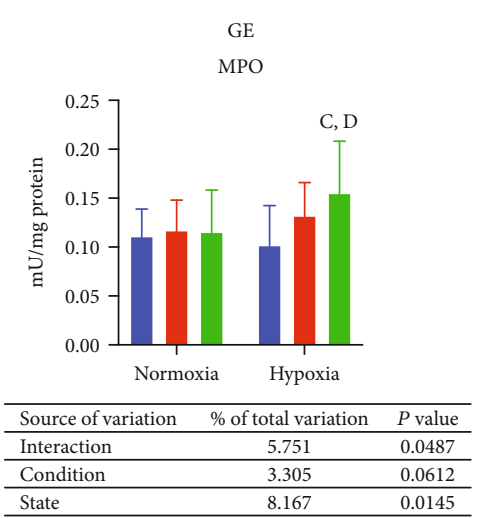

TNF-a

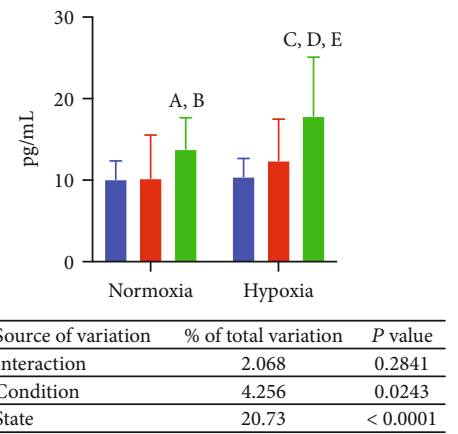

State

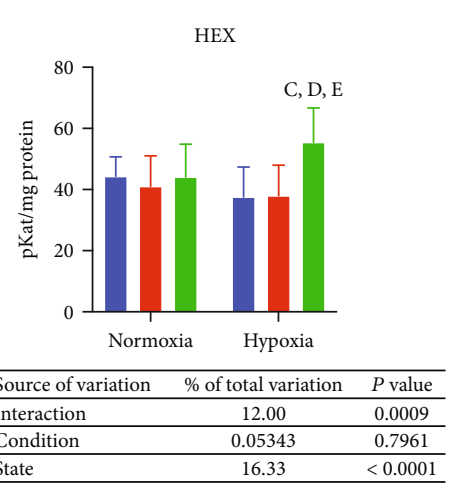

GLU

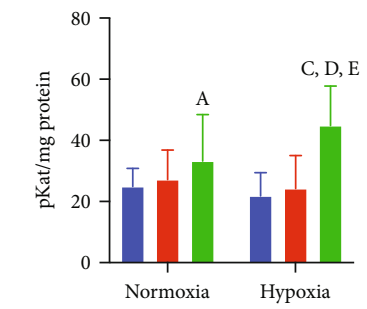

\begin{tabular}{lcc}
\hline Source of variation & $\%$ of total variation & $P$ value \\
\hline Interaction & 6.992 & 0.0097 \\
\hline Condition & 0.5052 & 0.4032 \\
\hline State & 28.03 & $<0.0001$ \\
\hline
\end{tabular}

$$
\begin{aligned}
& \text { Pre } \\
& \text { Post }
\end{aligned}
$$
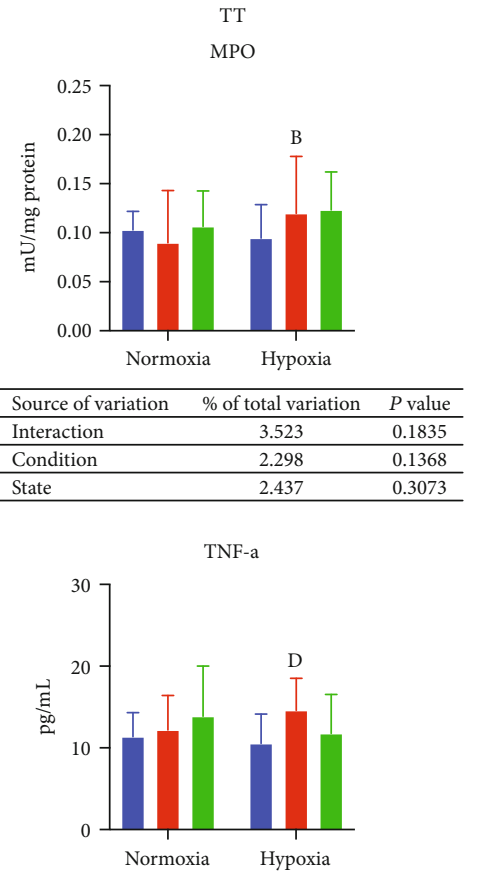

\begin{tabular}{lcc}
\hline Source of variation & $\%$ of total variation & $P$ value \\
\hline Interaction & 4.473 & 0.1130 \\
\hline Condition & 0.03636 & 0.8493 \\
\hline State & 5.389 & 0.0732 \\
\hline
\end{tabular}

State

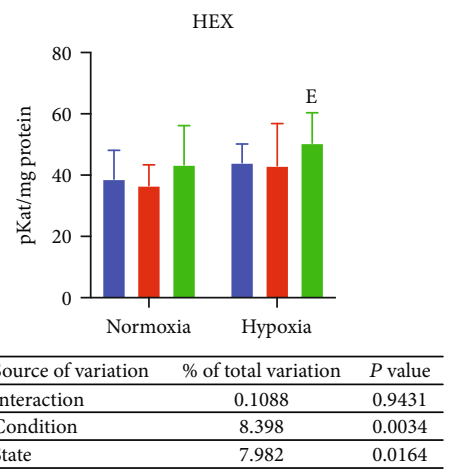

GLU

\begin{tabular}{|c|c|c|}
\hline Source of variation & $\%$ of total variation & $P$ value \\
\hline Interaction & 11.18 & 0.0014 \\
\hline Condition & 5.960 & 0.0072 \\
\hline State & 11.93 & 0.0009 \\
\hline
\end{tabular}

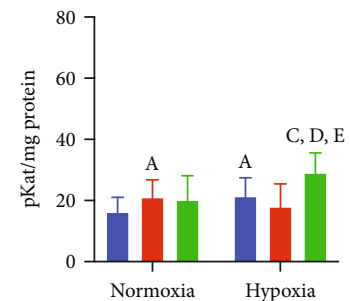

FIGURE 6: Effect on graded exercise until exhaustion (GE) and $30 \mathrm{~km}$ time trial (TT) on inflammation and lysosomal function in normoxia and hypoxia. GLU: $\beta$-glucuronidase; HEX: N-acetyl- $\beta$-hexosaminidase; MPO: myeloperoxidase; TNF- $\alpha$ : tumor necrosis factor-alpha. a, $p<0.05$ vs. the value before exercise in normoxia; $\mathrm{b}, p<0.05$ vs. the value after the exercise in normoxia; $c, p<0.05$ vs. the value after the exercise and $30 \mathrm{~min}$ of rest in normoxia; $\mathrm{d}, p<0.05$ vs. the value after the exercise in hypoxia; e, $p<0.05$ vs. the value after the exercise in hypoxia; $\mathrm{f}, p<0.05$ vs. the value after the exercise $30 \mathrm{~min}$ of rest in hypoxia. 

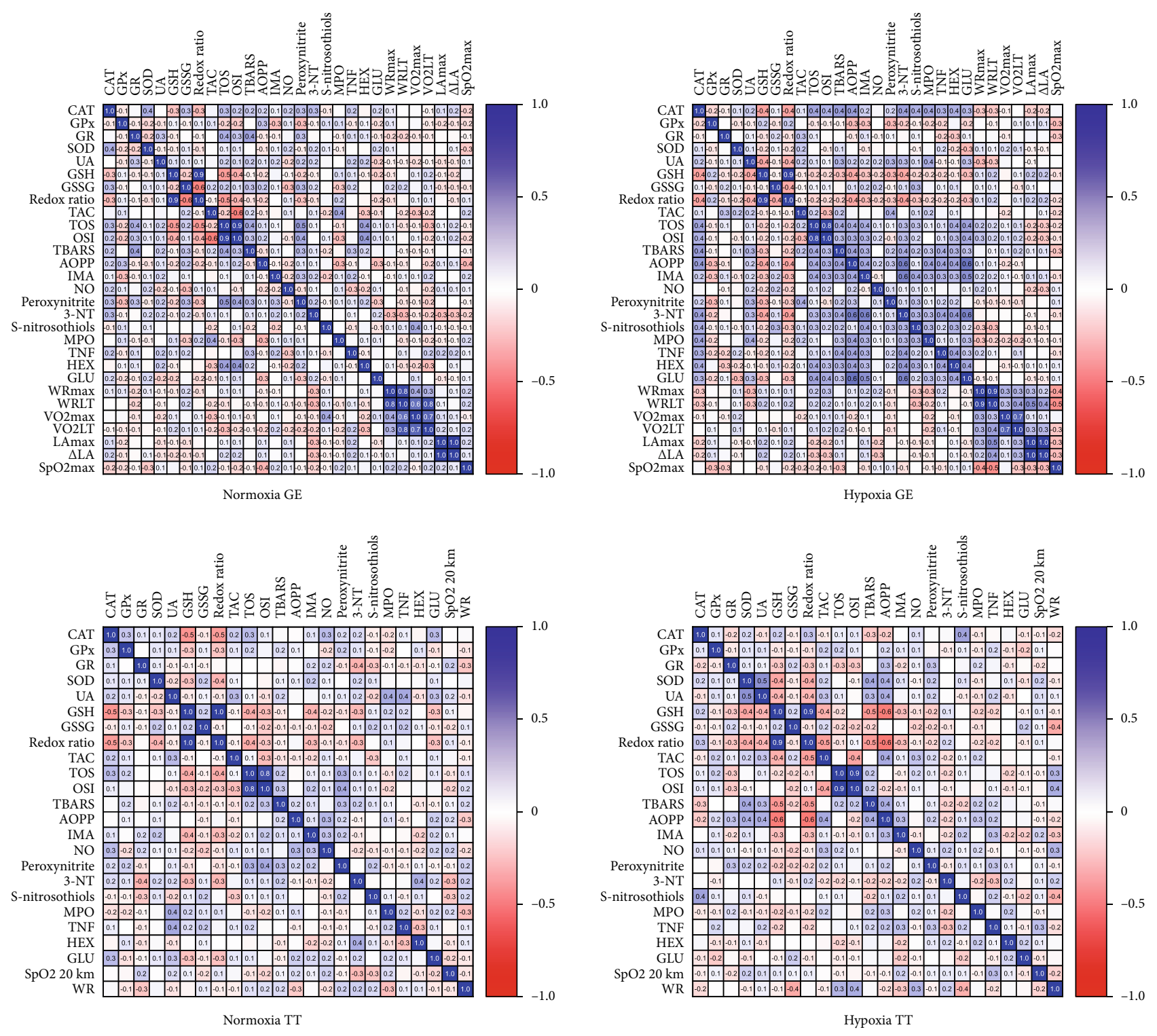

Figure 7: Correlation heat maps between redox and exercise parameters.

TAC $(r=-0.451 ; p=0.001)$, TBARS $(r=-0.468 ; p=0.001)$, and AOPP $(r=-0.615 ; p<0.0001)$ concentrations (Figure 7$)$.

\section{Discussion}

Our study is the first to evaluate the effect of different acute exercise protocols performed under normoxia and hypoxia on antioxidant status, oxidative and nitrosative damage, inflammation, and lysosomal function. We have shown that both graded exercise until exhaustion (GE) and $30 \mathrm{~km}$ time trial (TT) impair the efficiency of antioxidant systems and induce oxidative and nitrosative stress, with hypoxia causing more significant disruption in redox homeostasis and inflammation.

In recent years, there has been a marked increase in interest in mountain sports [67]. Apart from its undoubted advantages, this type of activity is not without health risks. Limited oxygen diffusion through the pulmonary capillaries contributes to tissue hypoxia and the overproduction of free radicals [32, 67]. ROS sources under these conditions include primarily reduced partial pressure of oxygen in the air (hypobaric hypoxia), intense physical activity, and autooxidation of catecholamines. Although various adaptive mechanisms can partially compensate for tissue hypoxia (e.g., hyperventilation, tachycardia, increased cardiac output, and enhanced hemoglobin and erythrocytes content), the most effective blood response does not appear until several days later [32].

The present study generally demonstrated the strengthening of enzymatic antioxidant systems during hypoxic exercise (GE: $\uparrow \mathrm{CAT}, \uparrow \mathrm{SOD}$; TT: $\uparrow \mathrm{CAT}$ vs. normoxia). Changes in the enzymatic antioxidant barrier may reflect various functional/pathophysiological states. The initial increase in enzyme activity is usually adaptation to higher production of ROS and RNS, whereas the subsequent decrease results from depletion of the antioxidant reserves. 
Of particular note are the erythrocyte enzymes (GPx and CAT) that degrade hydrogen peroxide. GPx plays a key role in $\mathrm{H}_{2} \mathrm{O}_{2}$ degradation at physiological concentrations by reducing hydrogen peroxide with the simultaneous conversion of GSH to its oxidized form (GSSG). However, under $\mathrm{H}_{2} \mathrm{O}_{2}$ overproduction, CAT exhibits greater enzymatic activity as evidenced by the Michaelis-Menten constant $(\mathrm{Km})$ for GPx $\left(1 \times 10^{-6} \mathrm{M}\right)$ and CAT $\left(2.4 \times 10^{-4} \mathrm{M}\right)$ [68, 69]. Although we did not directly assess the rate of free radical formation, the increase in CAT and decrease in GPx activity (versus normoxia) indicate a higher intensity of oxidative processes during hypoxic exercise. Enhanced plasma TOS in hypoxia also supports this hypothesis. It is well known that TOS determines the total amount of oxidants in a biological system [50]. Considering that free radicals can mutually enhance their production, TOS provides more information than evaluation of individual ROS/ RNS separately. However, what could constitute an additional source of free radicals in hypoxic exercise? During tissue hypoxia (as during tissue ischemia), xanthine dehydrogenase is converted to $\mathrm{XO}$, donating an electron to molecular oxygen. The reaction catalyzed by $\mathrm{XO}$ produces superoxide anions and hydrogen peroxide [2, 30, 31, 70], explaining the increase in SOD and CAT activity under hypoxic exercise. However, overactivation of nitric oxide synthases (NOS), especially inducible NOS (iNOS), also occurs in these conditions $[71,72]$. Excess nitric oxide (NO) concentrations inhibit cytochrome oxidase activity, which in turn intensifies $\mathrm{O}_{2}{ }^{-\bullet}$ production $[73,74]$. If the full $\mathrm{O}_{2}$ supply is restored, there is an increased formation of ROS referred to as the "oxygen paradox" $[75,76]$. Therefore, enhanced CAT activity observed in our study is not surprising (increase at each time interval versus normoxic exercise). Interestingly, the activity of antioxidant enzymes (CAT, SOD) and total oxidative capacity (TOS, OSI) were also relatively higher in high-intensity exercise until exhaustion (GE). If $\mathrm{O}_{2}$ supply to the cells is insufficient, energy is produced in the low-efficiency process of anaerobic glycolysis, leading to an increase in $\mathrm{H}^{+}$ions and lactate concentrations. The consequence is the loss of ability to maintain ionic homeostasis, particularly an increase in the extracellular concentration of $\mathrm{K}^{+}$and the accumulation of $\mathrm{Na}^{+}$and $\mathrm{Ca}^{2+}$, which is responsible for ROS overproduction [77, 78].

The signaling effects of hydrogen peroxide are associated with proteins recording changes in cellular redox status. The molecules responsible for transmitting the $\mathrm{H}_{2} \mathrm{O}_{2}$ signal to the nucleus are low molecular weight thiols, of which reduced glutathione is an essential intracellular source [79, 80]. Therefore, it is not surprising that GSH concentrations were significantly lower in athletes exercising in hypoxia compared to normoxia. Since GSSG concentrations and GR activity were unchanged, the decrease in GSH concentration may be due to the oxidation of enzymes responsible for glutathione synthesis or the formation of S-conjugates with glutathione and proteins. In addition to its antioxidant role, GSH participates in DNA replication and apoptosis and regulates the thiol groups of proteins in their reduced state $[81,82]$. Therefore, maintenance of adequate GSH levels is crucial for proper cellular function. In our study, despite strengthening the antioxidant barrier under hypoxia, there was a redox imbalance in favor of oxidative reactions (GE: $\uparrow$ TOS, $\downarrow$ redox ratio). This results in enhanced oxidation of plasma proteins (GE: $\uparrow$ AOPP, $\uparrow$ IMA; TT: $\uparrow$ AOPP) and lipids (GE: $\uparrow$ TBARS), which indicates the occurrence of systemic oxidative stress. This may be confirmed by the negative correlation between GSH concentration and TBARS and AOPP and between redox ratio and TAC, TBARS, and AOPP. Of particular note is the increase in IMA levels during hypoxic exercise. IMA is the earliest biomarker of tissue ischemia, whereas decreased oxygen saturation, ischemic reperfusion, acidosis, sodium/calcium pump dysfunction, and higher oxidative stress are factors causing conformational changes of albumin [57]. The increase in total antioxidant capacity may also be controversial (GE: $\uparrow$ TAC both after exercise and hypoxia vs. normoxia). Nevertheless, $70-80 \%$ of plasma TAC represents nonenzymatic uric acid (UA), with a robust prooxidant effect in high concentrations $[83,84]$. UA can generate free radicals by reacting with peroxynitrite or forming alkylated proteins, lipids, and carbohydrates [85]. Higher UA concentrations were observed in previous studies after one-time and regular high-intensity physical training [2, 20, 86-88]. UA is the end product of purine catabolism formed in a XO-catalyzed reaction from xanthine. Under hypoxic/ischemic conditions, hypoxanthine formed from ATP decomposition is accumulated in the cell and then metabolized to xanthine with the generation of ROS/RNS upon reperfusion $[89,90]$.

The $\mathrm{H}_{2} \mathrm{O}_{2}$ production may also be affected by nitric oxide metabolism [91, 92]. In our study, higher $\mathrm{NO}_{\mathrm{x}}$ bioavailability with a concomitant increase in CAT activity could be explained by intensified peroxynitrite $\left(\mathrm{ONOO}^{-}\right)$ formation influenced by an acute hypoxic intervention. Indeed, the superoxide radicals formed in the XO-catalyzed pathway react with $\mathrm{NO}$ to generate the highly reactive $\mathrm{ONOO}^{-}$[92]. Peroxynitrite is a powerful oxidizing and nitrating agent that initiates lipid peroxidation and oxidation of thiols/aromatic amino acids with an efficiency of at least 1000 -fold higher than hydrogen peroxide [93, 94]. Tyrosine residues are particularly sensitive to $\mathrm{ONOO}^{-}$damage; hence, the increase in 3-NT concentrations (both after exercise and in hypoxic conditions) is not surprising. Interestingly, peroxynitrite formation occurs typically under increased systemic inflammation $[93,94]$. This may be supported by the results of our study (GE: $\uparrow \mathrm{NO}, \uparrow \mathrm{ONOO}^{-}, \uparrow$ MPO, $\uparrow$ TNF- $\alpha$ ). Of particular note is higher MPO activity after hypoxic exercise. Indeed, MPO is released by neutrophils and monocytes during inflammatory cell activation [95]. It is involved in hypochlorous acid production, which exacerbates oxidative stress and initiates acute inflammation $[95,96]$. It is well known that higher secretion of cytokines, chemokines, and growth factors is a physiological response to decreased arterial blood $\mathrm{O}_{2}$ saturation and microdamage of muscle fibers. Activated neutrophils and macrophages can remove fragments of damaged muscle tissue induced by $\mathrm{NO}$ and $\mathrm{H}_{2} \mathrm{O}_{2}$ signaling $[97,98]$. Simultaneously, IL-1, IL-2, IL-6, and TNF- $\alpha$ may stimulate white blood cells to produce significant amounts of NO through prolonged iNOS activation $[99,100]$. In these conditions, $\mathrm{XO}$ and 
NOX are also induced, which, by positive feedback, enhances nitrosative cell injury (GE: $\uparrow \mathrm{NO}_{\mathrm{x}}, \uparrow \mathrm{ONOO}^{-}, \uparrow$ $3-\mathrm{NT}$ ). A consequence of enhanced inflammatory response and oxidative/nitrosative stress can be damage to the lysosomal membrane and the release of lysosomal enzymes into the circulation (GE: $\uparrow \mathrm{HEX}, \uparrow \mathrm{GLU}$ ). Interestingly, lysosomal dysfunction, mitochondrial energy metabolism, and impaired ion homeostasis are essential sources of ROS during physical exercise [101-103]. However, NO signaling activity may also depend on protein S-nitrosylation, as evidenced by increased S-nitrosothiols under hypoxic conditions. It is well known that NO-mediated protein S-nitrosylation plays a vital role in the adaptation to endurance exercise/hypoxia by increasing the PGC- $1 \alpha$ (peroxisome proliferator-activated receptor gamma coactivator 1-alpha) expression [104, 105]. Nevertheless, enhanced S-nitrosylation can also end in the formation of protein disulfide and a nitroxyl residue, which irreversibly alters the biological properties of proteins.

Physical exercise is indicated in both health and disease. Although our study does not explain it, individuals with diseases with oxidative stress etiology (e.g., metabolic, neurodegenerative, and immune diseases) should be cautious during acute hypoxic training. This may exacerbate disturbances in redox homeostasis and inflammation. Antioxidant supplementation during acute hypoxic exercise also remains an open question.

Unfortunately, our work has numerous limitations. These include the relatively small number of participants and the evaluation of only selected biomarkers of oxidative stress, inflammation, and lysosomal function. Our study also does not explain the molecular mechanisms responsible for the observed redox disturbances. Research on nonprofessional athletes is also essential.

To summarize, our study shows that even a single session of physical exercise disrupts the enzymatic and nonenzymatic antioxidant barrier leading to enhanced oxidative and nitrosative damage at a systemic level. High-intensity exercise of short duration alters redox homeostasis more than prolonged aerobic exercise, while hypoxia significantly exacerbates oxidative stress, inflammation, and lysosomal dysfunction in athletic subjects. Although we have reported the most commonly assessed circulating redox biomarkers, further studies are needed to elucidate the molecular basis of the observed relationships. Studies on larger groups of athletes are also advisable.

\section{Data Availability}

The datasets generated for this study are available on request to the corresponding author.

\section{Ethical Approval}

The investigation conformed with the principles outlined in the Declaration of Helsinki and was approved by the Bioethics Committee of the Medical University of Bialystok (approval no. R-I-002/325/2019).

\section{Conflicts of Interest}

There is no conflict of interests.

\section{Acknowledgments}

This work was supported by the National Science Centre, Poland (grant no. 2018/31/B/NZ7/02543) and by the Medical University of Bialystok, Poland (grant numbers SUB/1/ DN/21/002/3330 and SUB/1/DN/21/002/1209). Dr. Mateusz Maciejczyk was supported by the Foundation for Polish Science (FNP).

\section{References}

[1] H. Sies and D. P. Jones, "Reactive oxygen species (ROS) as pleiotropic physiological signalling agents," Nature Reviews. Molecular Cell Biology, vol. 21, pp. 363-383, 2020.

[2] F. He, J. Li, Z. Liu, C.-C. Chuang, W. Yang, and L. Zuo, "Redox mechanism of reactive oxygen species in exercise," Frontiers in Physiology, vol. 7, p. 486, 2016.

[3] V. I. Lushchak, "Free radicals, reactive oxygen species, oxidative stress and its classification," Chemico-Biological Interactions, vol. 224, pp. 164-175, 2014.

[4] P. D. Ray, B. W. Huang, and Y. Tsuji, "Reactive oxygen species (ROS) homeostasis and redox regulation in cellular signaling,” Cellular Signalling, vol. 24, no. 5, pp. 981-990, 2012.

[5] M. J. Morgan and Z. G. Liu, "Crosstalk of reactive oxygen species and NF- $\kappa \mathrm{B}$ signaling," Cell Research, vol. 21, no. 1, pp. 103-115, 2011.

[6] P. Poprac, K. Jomova, M. Simunkova, V. Kollar, C. J. Rhodes, and M. Valko, "Targeting free radicals in oxidative stressrelated human diseases," Trends in Pharmacological Sciences, vol. 38, no. 7, pp. 592-607, 2017.

[7] B. Choromańska, P. Myśliwiec, J. Dadan, A. Maleckas, A. Zalewska, and M. Maciejczyk, "Effects of age and gender on the redox homeostasis of morbidly obese people," Free Radical Biology \& Medicine, vol. 175, pp. 108-120, 2021.

[8] J. Styskal, H. Van Remmen, A. Richardson, and A. B. Salmon, "Oxidative stress and diabetes: what can we learn about insulin resistance from antioxidant mutant mouse models?," Free Radical Biology \& Medicine, vol. 52, no. 1, pp. 46-58, 2012.

[9] M. Maciejczyk, A. Zalewska, and K. Gerreth, "Salivary redox biomarkers in selected neurodegenerative diseases," Journal of Clinical Medicine, vol. 9, no. 2, p. 497, 2020.

[10] B. Halliwell, "Oxidative stress and neurodegeneration: where are we now?," Journal of Neurochemistry, vol. 97, no. 6, pp. 1634-1658, 2006.

[11] L. J. S. Da Fonseca, V. Nunes-Souza, M. O. F. Goulart, and L. A. Rabelo, "Oxidative stress in rheumatoid arthritis: what the future might hold regarding novel biomarkers and addon therapies," Oxidative Medicine and Cellular Longevity, vol. 2019, Article ID 7536805, 16 pages, 2019.

[12] K. Morawska, M. Maciejczyk, Ł. Popławski, A. PopławskaKita, A. Krętowski, and A. Zalewska, "Enhanced salivary and general oxidative stress in Hashimoto's thyroiditis women in euthyreosis," Journal of Clinical Medicine, vol. 9, no. 7, p. 2102, 2020.

[13] J. Zińczuk, K. Zaręba, J. Kamińska et al., "Association of tumour microenvironment with protein glycooxidation, DNA damage, and nitrosative stress in colorectal cancer," 
Cancer Management and Research, vol. 13, pp. 6329-6348, 2021.

[14] M. Valko, C. J. Rhodes, J. Moncol, M. Izakovic, and M. Mazur, "Free radicals, metals and antioxidants in oxidative stress-induced cancer," Chemico-Biological Interactions, vol. 160, no. 1, pp. 1-40, 2006.

[15] M. Finkler, D. Lichtenberg, and I. Pinchuk, "The relationship between oxidative stress and exercise," Journal of Basic and Clinical Physiology and Pharmacology, vol. 25, no. 1, pp. 111, 2014.

[16] S. K. Powers, R. Deminice, M. Ozdemir, T. Yoshihara, M. P. Bomkamp, and H. Hyatt, "Exercise-induced oxidative stress: friend or foe?," Journal of Sport and Health Science, vol. 9, pp. 415-425, 2020.

[17] C. Simioni, G. Zauli, A. M. Martelli et al., "Oxidative stress: role of physical exercise and antioxidant nutraceuticals in adulthood and aging," Oncotarget, vol. 9, pp. 17181-17198, 2018.

[18] M. Valko, D. Leibfritz, J. Moncol, M. T. D. Cronin, M. Mazur, and J. Telser, "Free radicals and antioxidants in normal physiological functions and human disease," The International Journal of Biochemistry \& Cell Biology, vol. 39, pp. 44-84, 2007.

[19] R. J. Bloomer and K. H. Fisher-Wellman, "Blood oxidative stress biomarkers: influence of sex, exercise training status, and dietary intake," Gender Medicine, vol. 5, no. 3, pp. 218228, 2008.

[20] T. Kawamura and I. Muraoka, "Exercise-induced oxidative stress and the effects of antioxidant intake from a physiological viewpoint," Antioxidants, vol. 7, p. 119, 2018.

[21] A. Vezzoli, L. Pugliese, M. Marzorati, F. R. Serpiello, A. La Torre, and S. Porcelli, "Time-course changes of oxidative stress response to high-intensity discontinuous training versus moderate-intensity continuous training in masters runners," PLoS One, vol. 9, article e87506, 2014.

[22] A. Z. Jamurtas, "Exercise-induced muscle damage and oxidative stress," Antioxidants, vol. 7, p. 50, 2018.

[23] J. Kruk, H. Y. Aboul-Enein, A. Kładna, and J. E. Bowser, "Oxidative stress in biological systems and its relation with pathophysiological functions: the effect of physical activity on cellular redox homeostasis," Free Radical Research, vol. 53, pp. 497-521, 2019.

[24] J. A. Sinex and R. F. Chapman, "Hypoxic training methods for improving endurance exercise performance," Journal of Sport and Health Science, vol. 4, pp. 325-332, 2015.

[25] B. Feriche, A. García-Ramos, A. J. Morales-Artacho, and P. Padial, "Resistance training using different hypoxic training strategies: a basis for hypertrophy and muscle power development," Sports Medicine - Open, vol. 3, p. 12, 2017.

[26] M. Czuba, O. Fidos-Czuba, K. Płoszczyca, A. Zając, and J. Langfort, "Comparison of the effect of intermittent hypoxic training vs. the live high, train low strategy on aerobic capacity and sports performance in cyclists in normoxia," Biology of Sport, vol. 35, pp. 39-48, 2018.

[27] M. Czuba, G. Bril, K. Płoszczyca et al., "Intermittent hypoxic training at lactate threshold intensity improves aiming performance in well-trained biathletes with little change of cardiovascular variables," BioMed Research International, vol. 2019, 1287517 pages, 2019.

[28] G. L. Semenza, "HIF-1 and mechanisms of hypoxia sensing," Current Opinion in Cell Biology, vol. 13, pp. 167-171, 2001.
[29] A. Wiśniewska, K. Płoszczyca, and M. Czuba, "Changes in erythropoietin and vascular endothelial growth factor following the use of different altitude training concepts," The Journal of Sports Medicine and Physical Fitness, vol. 60, 2020.

[30] J. Nagasawa, T. Kizaki, and H. Ohno, "Exercise and oxidative stress in hypoxia," Journal in Physical Fitness, Sports Medicine, vol. 2, pp. 481-486, 2013.

[31] C. Ballmann, G. McGinnis, B. Peters et al., "Exercise-induced oxidative stress and hypoxic exercise recovery," European Journal of Applied Physiology, vol. 114, pp. 725-733, 2014.

[32] G. Viscor, J. R. Torrella, L. Corral et al., "Physiological and biological responses to short-term intermittent hypobaric hypoxia exposure: from sports and mountain medicine to new biomedical applications," Frontiers in Physiology, vol. 9, p. 814, 2018.

[33] A. Raberin, E. Nader, J. Lopez Ayerbe et al., "Pro-oxidant/ antioxidant balance during a prolonged exposure to moderate altitude in athletes exhibiting exercise-induced hypoxemia at sea-level," Lifestyles, vol. 11, p. 228, 2021.

[34] L. J. S. da Fonseca, V. Nunes-Souza, S. Guedes Gda, G. Schettino-Silva, M. A. Mota-Gomes, and L. A. Rabelo, "Oxidative status imbalance in patients with metabolic syndrome: role of the myeloperoxidase/hydrogen peroxide axis," Oxidative Medicine and Cellular Longevity, vol. 2014, Article ID 898501, 14 pages, 2014.

[35] J. Carracedo, R. Ramírez-Carracedo, I. de Toda et al., "Protein carbamylation: a marker reflecting increased agerelated cell oxidation," International Journal of Molecular Sciences, vol. 19, 2018.

[36] S. Sabuncuoğlu, B. Kuşkonmaz, D. Uckun Çetinkaya, and H. Özgüneş, "Evaluation of oxidative and antioxidative parameters in pediatric hematopoietic SCT patients," Bone Marrow Transplantation, vol. 47, pp. 651-656, 2012.

[37] B. Choromańska, P. Myśliwiec, M. Łuba et al., "The impact of hypertension and metabolic syndrome on nitrosative stress and glutathione metabolism in patients with morbid obesity," Oxidative Medicine and Cellular Longevity, vol. 2020, Article ID 1057570, 10 pages, 2020.

[38] A. Hohl, J. da Silva Gullo, C. C. P. Silva et al., "Plasma levels of oxidative stress biomarkers and hospital mortality in severe head injury: a multivariate analysis," Journal of Critical Care, vol. 27, pp. 523.e11-523.e19, 2012.

[39] G. Colombo, F. Reggiani, D. Cucchiari et al., "Plasma protein carbonylation in haemodialysed patients: focus on diabetes and gender," Oxidative Medicine and Cellular Longevity, vol. 2018, Article ID 4149681, 12 pages, 2018.

[40] J. A. Detterich, H. Liu, S. Suriany et al., "Erythrocyte and plasma oxidative stress appears to be compensated in patients with sickle cell disease during a period of relative health, despite the presence of known oxidative agents," Free Radical Biology \& Medicine, vol. 141, pp. 408-415, 2019.

[41] H. Aebi, "[13] Catalase in vitro," Methods in Enzymology, vol. 105, pp. 121-126, 1984.

[42] D. E. Paglia and W. N. Valentine, "Studies on the quantitative and qualitative characterization of erythrocyte glutathione peroxidase," The Journal of Laboratory and Clinical Medicine, vol. 70, pp. 158-169, 1967.

[43] P. Żukowski, M. Maciejczyk, J. Matczuk et al., "Effect of Nacetylcysteine on antioxidant defense, oxidative modification, and salivary gland function in a rat model of insulin resistance," Oxidative Medicine and Cellular Longevity, vol. 2018, Article ID 6581970, 11 pages, 2018. 
[44] C. E. Mize and R. G. Langdon, "Hepatic glutathione reductase: I. Purification and general kinetic properties," The Journal of Biological Chemistry, vol. 237, pp. 1589-1595, 1962.

[45] H. P. Misra and I. Fridovich, "The role of superoxide anion in the autoxidation of epinephrine and a simple assay for superoxide dismutase," vol. 105, pp. 121-126, 1972.

[46] M. S. Moron, J. W. Depierre, and B. Mannervik, "Levels of glutathione, glutathione reductase and glutathione S-transferase activities in rat lung and liver," Biochimica et Biophysica Acta, General Subjects, vol. 582, pp. 67-78, 1979.

[47] E. Żebrowska, A. Chabowski, A. Zalewska, and M. Maciejczyk, "High-sugar diet disrupts hypothalamic but not cerebral cortex redox homeostasis," Nutrients, vol. 12, 2020.

[48] B. Choromańska, P. Myśliwiec, T. Kozłowski et al., “Antioxidant barrier and oxidative damage to proteins, lipids, and DNA/RNA in adrenal tumor patients," Oxidative Medicine and Cellular Longevity, vol. 2021, Article ID 5543531, 19 pages, 2021.

[49] O. Erel, "A novel automated direct measurement method for total antioxidant capacity using a new generation, more stable ABTS radical cation," Clinical Biochemistry, vol. 37, pp. 277-285, 2004.

[50] O. Erel, "A new automated colorimetric method for measuring total oxidant status," Clinical Biochemistry, vol. 38, pp. 1103-1111, 2005.

[51] J. Toczewska, M. Maciejczyk, T. Konopka, and A. Zalewska, "Total oxidant and antioxidant capacity of gingival crevicular fluid and saliva in patients with periodontitis: review and clinical study,” Antioxidants., vol. 9, 2020.

[52] S. Zengin, B. Al, P. Yarbil et al., "An assessment of oxidant/ antioxidant status in patients with snake envenomation," Emergency Medizinhistorisches Journal, vol. 31, pp. 48-52, 2014.

[53] J. A. Buege and S. D. Aust, "[30] Microsomal lipid peroxidation," Methods in Enzymology, vol. 52, pp. 302-310, 1978.

[54] N. Bakan, S. Taysi, Ö. Yilmaz et al., "Glutathione peroxidase, glutathione reductase, $\mathrm{Cu}-\mathrm{Zn}$ superoxide dismutase activities, glutathione, nitric oxide, and malondialdehyde concentrations in serum of patients with chronic lymphocytic leukemia," Clinica Chimica Acta, vol. 338, pp. 143-149, 2003.

[55] J. Škrha, M. Prázný, J. Hilgertová, J. Kvasnička, M. Kalousová, and T. Zima, "Oxidative stress and endothelium influenced by metformin in type 2 diabetes mellitus," European Journal of Clinical Pharmacology, vol. 63, pp. 1107-1114, 2007.

[56] K. Drygalski, E. Fereniec, A. Zalewska, A. Krętowski, M. Żendzian-Piotrowska, and M. Maciejczyk, "Phloroglucinol prevents albumin glycation as well as diminishes ROS production, glycooxidative damage, nitrosative stress and inflammation in hepatocytes treated with high glucose," Biomedicine \& Pharmacotherapy, vol. 142, p. 111958, 2021.

[57] D. Bar-Or, E. Lau, and J. V. Winkler, "A novel assay for cobalt-albumin binding and its potential as a marker for myocardial ischemia - a preliminary report," The Journal of Emergency Medicine, vol. 19, no. 4, pp. 311-315, 2000.

[58] B. Choromańska, P. Myśliwiec, M. Łuba et al., "Bariatric surgery normalizes protein glycoxidation and nitrosative stress in morbidly obese patients," Antioxidants., vol. 9, pp. 1-19, 2020.

[59] M. B. Grisham, G. G. Johnson, and J. R. Lancaster, "Quantitation of nitrate and nitrite in extracellular fluids," Methods in Enzymology, vol. 268, pp. 237-246, 1996.
[60] A. Skutnik-Radziszewska, M. Maciejczyk, I. Flisiak et al., "Enhanced inflammation and nitrosative stress in the saliva and plasma of patients with plaque psoriasis," Journal of Clinical Medicine, vol. 9, no. 3, p. 745, 2020.

[61] J. S. Beckman, H. Ischiropoulos, L. Zhu et al., "Kinetics of superoxide dismutase- and iron-catalyzed nitration of phenolics by peroxynitrite," Archives of Biochemistry and Biophysics, vol. 298, pp. 438-445, 1992.

[62] E. Bechtold and S. B. King, "Chemical methods for the direct detection and labeling of S-nitrosothiols," Antioxidants \& Redox Signaling, vol. 17, pp. 981-991, 2012.

[63] B. Choromańska, P. Myśliwiec, T. Kozłowski et al., "Crosstalk between nitrosative stress, inflammation and hypoxiainducible factor in patients with adrenal masses," Journal of Inflammation Research, vol. 14, pp. 6317-6330, 2021.

[64] M. F. Garça, M. Aslan, B. Tuna, A. Kozan, and H. Cankaya, "Serum myeloperoxidase activity, total antioxidant capacity and nitric oxide levels in patients with chronic otitis media," The Journal of Membrane Biology, vol. 246, no. 7, pp. 519524, 2013.

[65] M. Maciejczyk, A. Kossakowska, J. Szulimowska et al., "Lysosomal exoglycosidase profile and secretory function in the salivary glands of rats with streptozotocin-induced diabetes," Journal Diabetes Research, vol. 2017, article 9580398, 13 pages, 2017.

[66] J. Marciniak, A. Zalewska, J. Popko, and K. Zwierz, "Optimization of an enzymatic method for the determination of lysosomal $\mathrm{N}$-acetyl- $\beta$-D-hexosaminidase and $\beta$-glucuronidase in synovial fluid," Clinical Chemistry and Laboratory Medicine, vol. 44, pp. 933-937, 2006.

[67] M. Burtscher, M. Niedermeier, and H. Gatterer, "Editorial on the special issue on "Mountain Sports Activities: Injuries and Prevention"," International Journal of Environmental Research and Public Health, vol. 18, p. 1405, 2021.

[68] J. Zińczuk, M. Maciejczyk, K. Zaręba et al., "Pro-Oxidant Enzymes, Redox Balance and Oxidative Damage to Proteins, Lipids and DNA in Colorectal Cancer Tissue. Is Oxidative Stress Dependent on Tumour Budding and Inflammatory Infiltration?," Cancers, vol. 12, 2020.

[69] B. J. Day, "Catalase and glutathione peroxidase mimics," Biochemical Pharmacology, vol. 77, no. 3, pp. 285-296, 2009.

[70] L. Matta, T. S. Fonseca, C. C. Faria et al., "The effect of acute aerobic exercise on redox homeostasis and mitochondrial function of rat white adipose tissue," Oxidative Medicine and Cellular Longevity, vol. 2021, Article ID 4593496, 15 pages, 2021.

[71] E. Y. Dyakova, L. V. Kapilevich, V. G. Shylko, S. V. Popov, and Y. Anfinogenova, "Physical exercise associated with NO production: signaling pathways and significance in health and disease," Frontiers in Cell and Development Biology, vol. 3, 2015.

[72] A. V. Nosarev, L. V. Smagliy, Y. Anfinogenova, S. V. Popov, and L. V. Kapilevich, "Exercise and NO production: relevance and implications in the cardiopulmonary system," Frontiers in Cell and Development Biology, vol. 2, 2015.

[73] D. Z. Levett, B. O. Fernandez, H. L. Riley et al., "The role of nitrogen oxides in human adaptation to hypoxia," Scientific Reports, vol. 1, p. 109, 2011.

[74] R. A. Dweik, "Nitric oxide, hypoxia, and superoxide: the good, the bad, and the ugly!," Thorax, vol. 60, pp. 265-267, 2005. 
[75] A. Hadanny and S. Efrati, "The hyperoxic-hypoxic paradox," Biomolecules, vol. 10, p. 958, 2020.

[76] S. Dane, S. Taysi, M. Gul, F. Akcay, and A. Gunal, "Acute exercise induced oxidative stress is prevented in erythrocytes of male long distance athletes," Biology of Sport, vol. 25, 2008.

[77] J. T. Reeves, E. E. Wolfel, H. J. Green et al., “Oxygen transport during exercise at altitude and the lactate paradox: lessons from Operation Everest II and Pikes Peak," Exercise and Sport Sciences Reviews, vol. 20, pp. 275-296, 1992.

[78] P. Moghetti, E. Bacchi, C. Brangani, S. Donà, and C. Negri, "Metabolic effects of exercise," Sports Endocrinology, vol. 47, pp. 44-57, 2016.

[79] H. S. Marinho, C. Real, L. Cyrne, H. Soares, and F. Antunes, "Hydrogen peroxide sensing, signaling and regulation of transcription factors," Redox Biology, vol. 2, pp. 535-562, 2014.

[80] C. C. Winterbourn, "Hydrogen peroxide reactivity and specificity in thiol-based cell signalling," Biochemical Society Transactions, vol. 48, pp. 745-754, 2020.

[81] K. Aquilano, S. Baldelli, and M. R. Ciriolo, "Glutathione: New roles in redox signaling for an old antioxidant," Frontiers in Pharmacology, vol. 5, 2014.

[82] M. Jozefczak, T. Remans, J. Vangronsveld, and A. Cuypers, "Glutathione is a key player in metal-induced oxidative stress defenses," International Journal of Molecular Sciences, vol. 13, pp. 3145-3175, 2012.

[83] I. Peluso and A. Raguzzini, "Salivary and urinary total antioxidant capacity as biomarkers of oxidative stress in humans," Pathology Research International, vol. 2016, 14 pages, 2016.

[84] A. Janaszewska and G. Bartosz, "Assay of total antioxidant capacity: comparison of four methods as applied to human blood plasma," Scandinavian Journal of Clinical and Laboratory Investigation, vol. 62, pp. 231-236, 2002.

[85] C. Gersch, S. P. Palii, W. Imaram et al., "Reactions of peroxynitrite with uric acid: formation of reactive intermediates, alkylated products and triuret, and in vivo production of triuret under conditions of oxidative stress," Nucleosides, Nucleotides \& Nucleic Acids, vol. 28, pp. 118-149, 2009.

[86] S. Mohamed, N. Lamya, and M. Hamda, "Effect of maximal versus supra-maximal exhausting race on lipid peroxidation, antioxidant activity and muscle-damage biomarkers in longdistance and middle-distance runners, Asian," The Journal of Sports Medicine, vol. 7, pp. e27902-e27902, 2016.

[87] C. Thomas, P. Sirvent, S. Perrey, E. Raynaud, and J. Mercier, "Relationships between maximal muscle oxidative capacity and blood lactate removal after supramaximal exercise and fatigue indexes in humans," Journal of Applied Physiology, vol. 97, pp. 2132-2138, 2004.

[88] M. Wiecek, M. Maciejczyk, J. Szymura, and Z. Szygula, “Sex differences in oxidative stress after eccentric and concentric exercise," Redox Report, vol. 22, pp. 478-485, 2017.

[89] G. Glantzounis, E. Tsimoyiannis, A. Kappas, and D. Galaris, "Uric acid and oxidative stress," Current Pharmaceutical Design, vol. 11, no. 32, pp. 4145-4151, 2005.

[90] P. Higgins, J. Dawson, and M. Walters, "The potential for xanthine oxidase inhibition in the prevention and treatment of cardiovascular and cerebrovascular disease," Cardiovascular Psychiatry and Neurology, vol. 2009, Article ID 282059, 9 pages, 2009.
[91] S. Thomas, S. Kotamraju, J. Zielonka, D. R. Harder, and B. Kalyanaraman, "Hydrogen peroxide induces nitric oxide and proteosome activity in endothelial cells: a bell-shaped signaling response," Free Radical Biology \& Medicine, vol. 42, pp. 1049-1061, 2007.

[92] W. Xie, J. L. Parker, and C. L. Heaps, "Effect of exercise training on nitric oxide and superoxide $/ \mathrm{H}_{2} \mathrm{O}_{2}$ signaling pathways in collateral-dependent porcine coronary arterioles," Journal of Applied Physiology, vol. 112, pp. 1546-1555, 2012.

[93] R. Radi, "Nitric oxide, oxidants, and protein tyrosine nitration," Proceedings of the National Academy of Sciences of the United States of America, vol. 101, no. 12, pp. 4003-4008, 2004.

[94] R. Radi, J. S. Beckman, K. M. Bush, and B. A. Freeman, "Peroxynitrite-induced membrane lipid peroxidation: the cytotoxic potential of superoxide and nitric oxide," Archives of Biochemistry and Biophysics, vol. 288, no. 2, pp. 481-487, 1991.

[95] D. Odobasic, A. R. Kitching, and S. R. Holdsworth, "Neutrophil-mediated regulation of innate and adaptive immunity: the role of myeloperoxidase," Journal of Immunology Research, vol. 2016, Article ID 2349817, 11 pages, 2016.

[96] J. P. Eiserich, S. Baldus, M. L. Brennan et al., "Myeloperoxidase, a leukocyte-derived vascular NO oxidase," Science (80.), vol. 296, no. 5577, pp. 2391-2394, 2002.

[97] T. A. Butterfield, T. M. Best, and M. A. Merrick, "The dual roles of neutrophils and macrophages in inflammation: a critical balance between tissue damage and repair," Journal of Athletic Training, vol. 41, no. 4, pp. 457-465, 2006.

[98] F. Pizza, J. Peterson, J. Baas, and T. Koh, "Interplay between neutrophils and skeletal muscle after exercise. What's going on?," Physiology News, vol. 61, no. Winter 2005, pp. 32-33, 2006.

[99] E. Supruniuk, M. Maciejczyk, A. Zalewska, J. Górski, and A. Chabowski, "Blood profile of cytokines, chemokines, growth factors, and redox biomarkers in response to different protocols of treadmill running in rats," International Journal of Molecular Sciences, vol. 21, 2020.

[100] É. Cerqueira, D. A. Marinho, H. P. Neiva, and O. Lourenço, "Inflammatory effects of high and moderate intensity exercise-a systematic review," Frontiers in Physiology, vol. 10, 2020.

[101] Z. Zhang, P. Yue, T. Lu, Y. Wang, Y. Wei, and X. Wei, "Role of lysosomes in physiological activities, diseases, and therapy," Journal of Hematology \& Oncology, vol. 14, p. 79, 2021.

[102] A. Salminen, K. Hongisto, and V. Vihko, "Lysosomal changes related to exercise injuries and training-induced protection in mouse skeletal muscle," Acta Physiologica Scandinavica, vol. 120, pp. 15-19, 1984.

[103] H. Nohl and L. Gille, "Lysosomal ROS formation," Redox Report, vol. 10, pp. 199-205, 2005.

[104] J. Bouviere, R. S. Fortunato, C. Dupuy, J. P. Werneck-de-Castro, D. P. Carvalho, and R. A. Louzada, "Exercise-stimulated ROS sensitive signaling pathways in skeletal muscle," Antioxidants., vol. 10, p. 537, 2021.

[105] T. Geng, P. Li, M. Okutsu et al., "PGC-1alpha plays a functional role in exercise-induced mitochondrial biogenesis and angiogenesis but not fiber-type transformation in mouse skeletal muscle," American Journal of Physiology. Cell Physiology, vol. 298, pp. C572-C579, 2010. 